
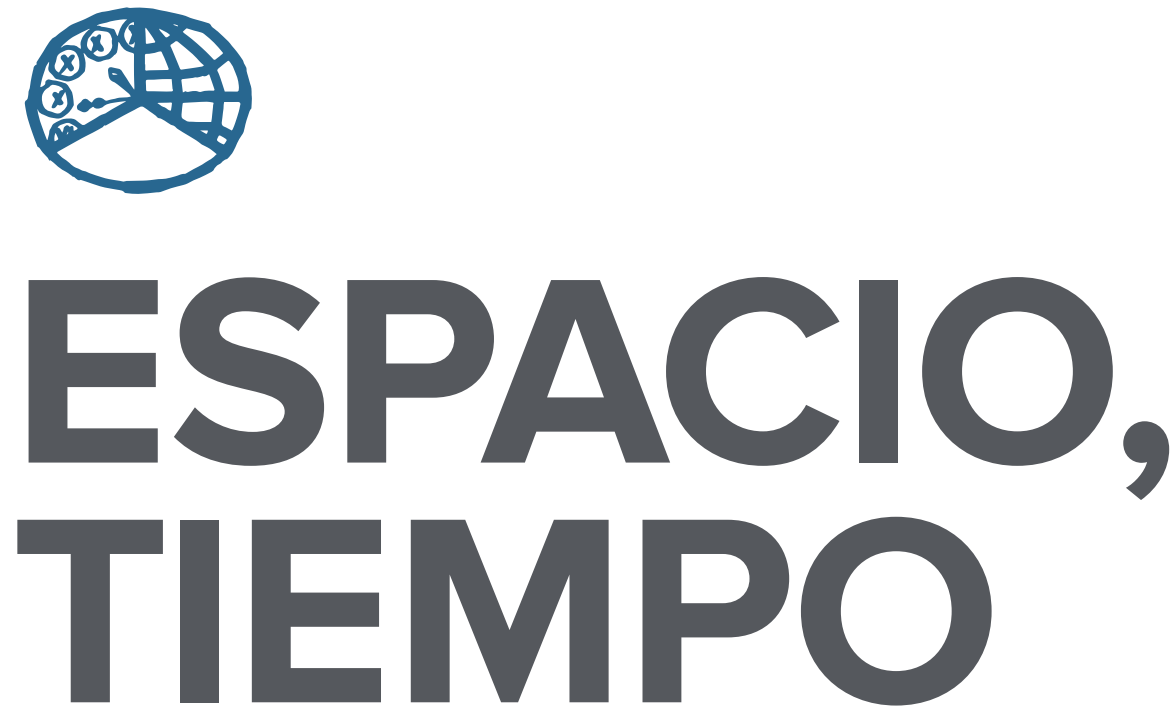

AÑO 2019 NUEVA ÉPOCA ISSN 1130-4715

E-ISSN 2340-1478
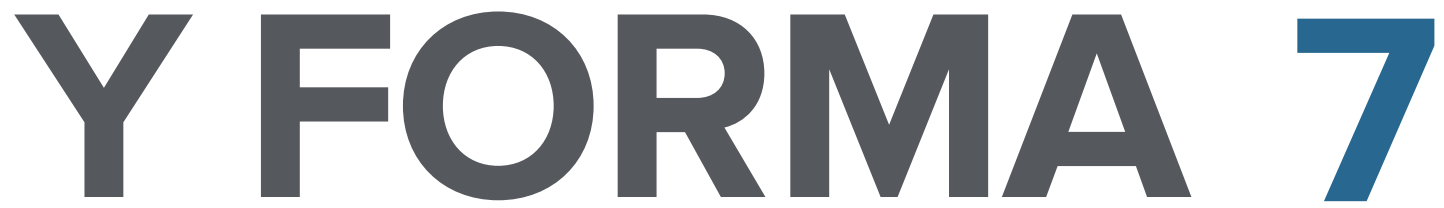

SERIE VII HISTORIA DEL ARTE

REVISTA DE LA FACULTAD DE GEOGRAFÍA E HISTORIA 


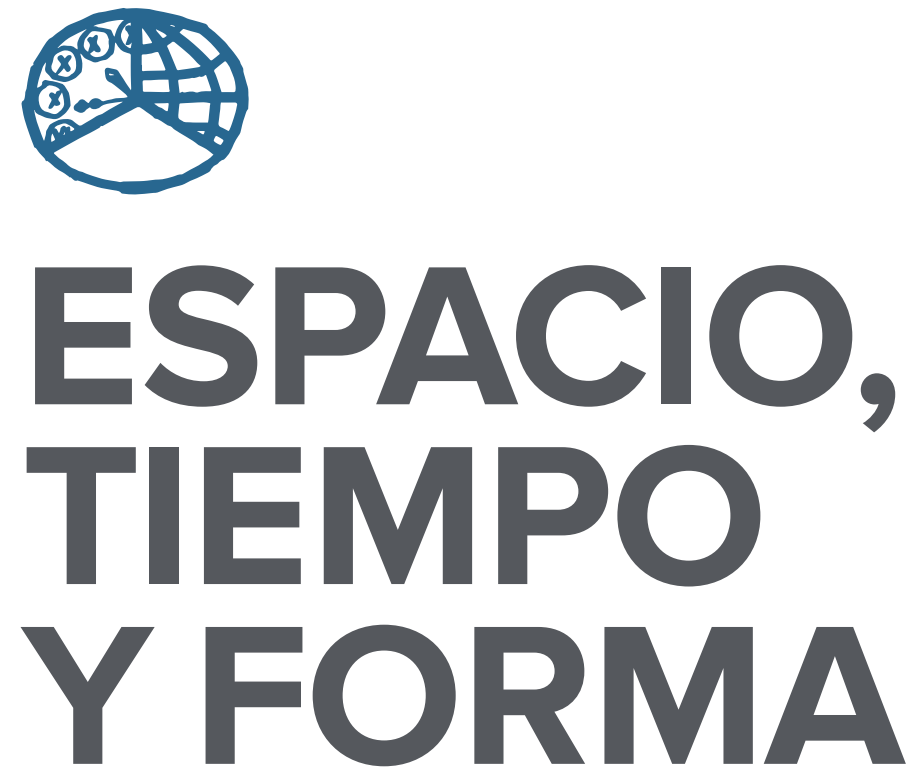

AÑO 2019

NUEVA ÉPOCA

ISSN $1130-4715$

E-ISSN 2340-1478

SERIE VII HISTORIA DEL ARTE

REVISTA DE LA FACULTAD DE GEOGRAFİA E HISTORIA

DOI: http://dx.doi.org/10.5944/etfvii.7.2019

\section{UกED}

UNIVERSIDAD NACIONAL DE EDUCACIÓN A DISTANCIA 
La revista Espacio, Tiempo y Forma (siglas recomendadas: ETF), de la Facultad de Geografía e Historia de la UNED, que inició su publicación el año 1988, está organizada de la siguiente forma:

$$
\begin{aligned}
& \text { SERIE I - Prehistoria y Arqueología } \\
& \text { SERIE II - Historia Antigua } \\
& \text { SERIE III - Historia Medieval } \\
& \text { SERIE IV - Historia Moderna } \\
& \text { SERIE V - Historia Contemporánea } \\
& \text { SERIE VI - Geografía } \\
& \text { SERIE VII - Historia del Arte }
\end{aligned}
$$

Excepcionalmente, algunos volúmenes del año 1988 atienden a la siguiente numeración:

$$
\begin{aligned}
& \mathrm{N}^{\circ} 1 \text { - Historia Contemporánea } \\
& \mathrm{N}^{\circ} 2 \text { - Historia del Arte } \\
& \mathrm{N}^{\circ} 3 \text { - Geografía } \\
& \mathrm{N} .^{\circ} 4 \text { - Historia Moderna }
\end{aligned}
$$

ETF no se solidariza necesariamente con las opiniones expresadas por los autores.

UNIVERSIDAD NACIONAL DE EDUCACIÓN A DISTANCIA

Madrid, 2019

SERIE VII · HISTORIA DEL ARTE (NUEVA ÉPOCA) N..$^{\circ} 72019$

ISSN $1130-4715 \cdot$ E-ISSN 2340-1478

DEPÓSITO LEGAL

$M-21.037-1988$

URL

ETF VII · HISTORIA DEL ARTE $\cdot$ http://revistas.uned.es/index.php/ETFVII

DISEÑO Y COMPOSICIÓN

Carmen Chincoa Gallardo · http://www.laurisilva.net/cch

Impreso en España · Printed in Spain 


\section{MISCELÁNEA • MISCELLANY}





\title{
LOS CINEMATÓGRAFOS DISEÑADOS POR FERNANDO PERIANES: UNA LECTURA PATRIMONIAL EN TORNO A LOS EDIFICIOS DE OCIO EN LA PROVINCIA DE CÁCERES
}

\author{
THE MOVIE-THEATERS PLANNED BY \\ FERNANDO PERIANES: A HERITAGE READING \\ AROUND LEISURE ARCHITECTURE IN \\ THE PROVINCE OF CÁCERES (SPAIN)
}

\author{
Angélica García-Manso \\ Recibido: 23/08/2018 - Aceptado: 12/11/2018 \\ DOI: http://dx.doi.org/10.5944/etfvii.2019.22453
}

\begin{abstract}
Resumen
Uno de los proyectistas de edificios de ocio más importante por el número y el carácter de los inmuebles construidos en la provincia de Cáceres durante el pasado siglo XX fue el aparejador Fernando Perianes. En sus intervenciones, integra los cinematógrafos que diseña, normalmente sobre espacios preexistentes, con el urbanismo y la identidad del lugar en el que se ubican, además de aportar modernidad a las poblaciones mediante construcciones que permiten la evolución de la arquitectura rural sin provocar estridencias en el entorno. Se analiza una docena larga de salas de proyecciones a partir de fuentes fotográficas y documentales, como herramientas didácticas y de generación de storytelling sobre la memoria popular toda vez que el uso pensado como cines ha desaparecido.
\end{abstract}

Palabras clave

Patrimonio; Arquitectura de ocio; Cinematógrafos; Cáceres; Fernando Perianes.

\section{Abstract}

One of the designers of buildings of leisure architecture more important by the number and the character of the buildings constructed in the Caceres province (Spain) during the $20^{\text {th }}$ century was the engineer Fernando Perianes. In his interventions, he integrates the movie theaters he designs, usually on pre-existing spaces, with the urbanism and the identity of the place where they are located, as well as bringing modernity to the populations through constructions that allow the evolution of rural architecture without discordant effects in the citizen environment. Over

1. Universidad de Extremadura (Grupo de Investigación MUSAEXI: Humoo4). C. e.: angmanso@unex.es 
than a dozen of movie-theaters by Perianes are analysed from photographic and documentary sources, such as didactic and storytelling tools on popular memory, since the use of the cinemas has disappeared.

Keywords

Heritage; Leisure architecture; Movie theaters; Cáceres; Fernando Perianes. 


\section{INTRODUCCIÓN: FERNANDO PERIANES}

Fernando Perianes Presumido (Zarza la Mayor, I908-Cáceres, I985) ejerció el oficio de aparejador, cuyos estudios desarrolló en buena medida a distancia y con cierta dilación en el tiempo desde que los inició con más de veinte años de edad; se trata, además, de una formación que se vio interrumpida por la Guerra Civil. Será después de la contienda cuando se instala en la ciudad de Cáceres, tras desarrollar algunos proyectos y reformas en su comarca de procedencia. Su trabajo en los servicios administrativos de Obras Públicas sitos en la capital cacereña, sobre todo en lo que se refiere a la Diputación Provincial, en la que culminó su carrera profesional, le permitieron estar en contacto con iniciativas arquitectónicas del conjunto de la provincia. Su biografía como aparejador se inicia, pues, en los años cuarenta, cuando contaba con más de treinta años de edad, y adquiere su apogeo entre los años finales de los cuarenta y los años finales de los 6o, dos décadas en las que firma un número importante de proyectos, sobre todo de edificios públicos, sean éstos de iniciativa administrativa o de carácter privado, como los cinematógrafos, en cuya atención se centrarán las presentes páginas. Se trata de inmuebles con una característica esencial, su naturaleza rural, cuando los estudios, salvo excepciones y de forma predominante, se han centrado en proyectos urbanos ${ }^{2}$, si bien existen trabajos modélicos sobre la singular percepción antropológica que poseen los cines rurales 3 .

Entre los proyectos de Fernando Perianes de iniciativa institucional se cuentan, entre otros ámbitos oficiales, oficinas de correos, casas consistoriales y cuarteles de la Guardia Civil. También trabajó para la institución eclesiástica, con reformas de templos, algunos de la osadía de la Ermita de la Virgen de la Vega en Moraleja, o, con un carácter más puntual, las del Convento de El Palancar y de la iglesia principal de Zarza la Mayor, por citar únicamente tres ejemplos. En la capital intervino en restauraciones monumentales, caso del Convento de Santo Domingo, pero, sobre todo, relacionadas con edificios dependientes de la Diputación Provincial, como el Conventual de San Francisco y la propia sede de la institución en la ciudad antigua cacereña ${ }^{4}$. De igual forma, ejecutó importantes intervenciones en viviendas particulares, entre las que suele destacarse la Casa de los Iglesias, números 25 y 27 de la Calle San Antón en la ciudad de Cáceres, cuyo proyecto originario es del año I932, obra del arquitecto Ángel Pérez, con el que llegará a colaborar en diferentes ocasiones a lo largo de su vida profesional's.

2. Cf. Balsalobre García, Juana María: Arquitectura de salones, pabellones cinematográficos y cines. Alicante, Universidad de Alicante, 2006; ArIAS Romero, Salvador Mateo: Granada: Sociedad, Cine y Arquitectura. Granada, Zumaya Editorial, 2011; o SÁNCHEZ-GARCíA, Jesús Ángel: «Las salas de cine en España: Evolución histórica, arquitectura y situación actual», Patrimonio Cultural de España, 10, 2015, pp. 97-109.

3. Caso de los dedicados a la Montaña Palentina en Blanco Esteban, Óscar \& Román Ibáñez, Wifredo: CastiIlos de ceniza. Historia de los cines en la Montaña Palentina. Salamanca, Cultura \& Comunicación, 2013; o, también, los que se pueden espigar en SÁIz VIADERO, José Ramón (ed.): La exhibición cinematográfica en España: de los barracones de feria a los palacios de cine. Santander, Consejería de Cultura, Turismo y Deportes, 2009.

4. Vid. Ramos Rubio, José Antonio \& Méndez Hernán, Vicente: «Aportaciones inéditas del Monasterio de San Francisco el Real de Cáceres. Planos», Alcántara. Revista del Seminario de Estudios Cacereños, 64, 2006, pp. 55-93.

5. Cf. Collantes Estrada, María Jesús: Arquitectura del llano y pseudo-modernista en Cáceres. Cáceres, Caja de Ahorros y Monte de Piedad de Cáceres, 1979; LozAno BARTolozzı, María del Mar: «Pérez Rodríguez, Ángel», Gran 
Con este corpus, aunque mínimamente descrito, es quizá junto al placentino Francisco Mirón Calzada, de una generación anterior, uno de los aparejadores con mayor influencia en la provincia cacereña en los años cincuenta y sesenta del pasado siglo, y su impronta se aprecia todavía hoy en la imagen urbana de la capital y pueblos, si bien ésta está siendo difuminada por el paso de los años. Por lo demás, en relación con Extremadura, salvo los estudios mencionados a propósito del arquitecto Ángel Pérez, se puede decir que apenas se ha hecho un abordaje de conjunto sobre la obra de determinado proyectista a lo largo de la región o sobre la personalidad que la arquitectura contemporánea posee en el entorno ${ }^{6}$.

De cualquier forma, resulta difícil conocer de forma directa la cultura arquitectónica del aparejador, por cuanto su biografía, según se ha señalado, muestra cierta mezcla entre el autodidactismo, dado que estudió a distancia ya mayor, con la Guerra Civil como laguna en su formación, y la influencia que recibe, una vez asentado en la capital cacereña, de arquitectos como Ángel Pérez o Fernando Hurtado Collar, para los que trabaja. Su dinamismo profesional se centra casi en exclusiva en la provincia de Cáceres, que conoce prácticamente en todos sus rincones, sin que se conozcan otros viajes formativos de relieve, toda vez que comienza el desarrollo de su profesión en unos momentos de enormes dificultades socioeconómicas como son los de la posguerra.

Desde una perspectiva estética, la superación de la arquitectura popular o vernácula en zonas rurales (y la provincia de Cáceres en su práctica totalidad, excepción hecha de contadas localidades, era ejemplo de este tipo de «skyline» $\mathrm{u}$ horizonte urbanístico) no se produce en el siglo XX, sino que se da, fundamentalmente, a finales del siglo XIX, cuando, en paralelo con la tradicional monumentalidad religiosa, se promueven edificios cívicos de mayor relevancia arquitectónica, sobre todo ayuntamientos. A este respecto, la combinación de arqueado y adintelamiento en una misma fachada tripartita, típica de la arquitectura consistorial, es de origen centroeuropeo y se generaliza gracias al papel de los arquitectos municipales de las capitales de provincia, como, en el caso de Cáceres de manera relevante, el arquitecto Emilio María Rodríguez García, con orígenes cacereños él mismo, que fue titulado en el año i875. Salvo excepciones, no sucede en el ámbito rural que se traslade esa disposición estética de plantas con arcos, sea en portadas o ventanas, y otras adinteladas a edificios de ocio: solamente se conocen dos casos, realmente singulares por lo demás, en la provincia de Cáceres: el Teatro Luis Rivera de la población de Valencia de Alcántara, inaugurado en I893, y la fachada del Salón Romero en Plasencia (luego Cine Romero), obra del mencionado Emilio $\mathrm{M}^{\mathrm{a}}$ Rodríguez, quien en el año I902 interviene con la citada estética con un frente de fábrica sobre un edificio que era de arquitectura desmontable y que había sido instalado en la población casi

Enciclopedia Extremeña, 8. Mérida (Badajoz), Ediciones Extremeñas, 1989-1992, pp. 89-90; LozANo BARTOLOzZI, María del Mar \& CRUz ViLLALón, María: La arquitectura en Badajoz y Cáceres: del eclecticismo fin de siglo al racionalismo (1890-1940). Mérida, Asamblea de Extremadura, 1995; O HURTADo URRUTIA, Miguel: «De nuestra memoria cultural. Ángel Pérez, Arquitecto (1897-1977)», Ateneo, revista del Ateneo de Cáceres, 11, 2010, pp. 10-13.

6. Cf. González GonzÁlez, José Manuel: Arquitectura contemporánea en Extremadura. Mérida (Badajoz), Editora Regional de Extremadura, 2011. 
una década antes, en I893. En fin, la existencia de vanos centrales en el frontal constituye, además, uno de los elementos idiosincráticos de la arquitectura de los cinematógrafos ${ }^{7}$, reflejando tales concavidades una de las características de los espacios de proyección objeto de estudio.

Es precisamente en la transferencia que se hace de este modelo arquitectónico del siglo XIX a los inmuebles de ocio ya en pleno siglo XX y, por ello, resulta perceptible de manera relevante en el ocio cinematográfico, donde sí posee un relieve llamativo en el entorno provincial cacereño Fernando Perianes. Ahora bien, según exponemos, su conocimiento a este respecto no es académico, sino fruto de su experiencia sobre el terreno y su contacto con arquitectos de la importancia del ya citado Ángel Pérez Rodríguez. En lo que se refiere a la posible influencia decimonónica y primisecular, por razones biográficas obvias, aunque Perianes no llegó a conocer a Emilio María Rodríguez, no cabe duda de que sí reconoció sus edificios, caso de los ayuntamientos de poblaciones del relieve de Navalmoral de la Mata, Logrosán, Arroyomolinos de Montánchez, Aldea del Cano o Santiago de Carbajo, además de otros edificios públicos como escuelas, cuarteles o mercados, de menor entidad que las casas consistoriales ${ }^{8}$. En este contexto, en ocasiones, como en el caso de Albalá, al ser la casa consistorial el edificio de mayor relevancia de la población al margen de los inmuebles eclesiásticos, Perianes se permitirá la evocación del edificio administrativo en la arquitectura de ocio que promueve.

En un orden de cosas diferente, el solapamiento de competencias entre arquitectos y aparejadores, a pesar de estar regulado, resulta problemático en varios frentes: de un lado, las necesidades de reconstrucción de la posguerra y el apremio asociado de contar con profesionales suficientes en entornos muy distintos, desde pequeños núcleos rurales hasta capitales de provincia, provocó en los primeros años un inevitable relajamiento en el control del diseño y edificación de inmuebles de todo tipo, de las actuaciones sobre edificios preexistentes y de su certificación constructiva, de forma que en muchas ocasiones se recurre no a un aparejador, sino a un «maestro de obras» local al servicio de las administraciones menores para la elaboración de proyectos, intervenciones y vistos buenos últimos9.

A este respecto, el caso de Perianes resulta en buena medida paradigmático, sobre todo a partir de la iniciativa personal que era capaz de desplegar a la hora de respaldar proyectos empresariales relacionados con la arquitectura del ocio, en particular con los cinematógrafos -y, más puntualmente, con otros locales-: al residir en la ciudad de Cáceres podía hacer de correa de transmisión entre la administración

\footnotetext{
7. Según las evocaciones de carácter reflexivo de Blanco-Lorenzo, Enrique M. \& Sabín Díaz, Patricia: «El hueco de fachada en la arquitectura del cine», en Álvarez Areces, Miguel Ángel (ed.), Patrimonio y arqueología de la industria del cine, Gijón, CICEES (Centro de Iniciativas Culturales y Sociales), 2010, pp. 151-160.

8. Cf. Lozano Bartolozzi, María del Mar: «Urbanismo y arquitectura en Extremadura en torno a 1898, una etapa de tránsito», Revista de Estudios Extremeños, 54, 1998, pp. 973-1016; también LozANo BARTOLOzzI, María del Mar: «Agua, higiene, espacio. Proyectos a caballo entre dos siglos del arquitecto Emilio $\mathrm{M}^{\mathrm{a}}$ Rodríguez en poblaciones de la cuenca del Tajo», Boletín de Arte, 34, 2013, pp. 135-160.

9. Vid. Arenas Cabello, Francisco Julio: «La titulación de Aparejador. Evolución histórica de sus atribuciones profesionales: desde el Decreto Luján de 1855 hasta la Ley 38/1999 de ordenación de la edificación», Boletín de la Facultad de Derecho de la U.N.E.D., 26, 2005, pp. 15-31.
} 
provincial y los inmuebles de cuya construcción o reforma se responsabilizaba fuera de la capital. Para ello aprovechaba el reconocimiento legal que contaban los aparejadores para proponer proyectos arquitectónicos si se daban básicamente dos circunstancias: no superar un importe económico determinado por la administración (es decir, la envergadura del edificio se calculaba en función de sus costes) y que no se contara en el lugar con profesionales de rango superior. Aunque se trataba de una legislación vigente hasta el año i935, lo cierto es que continuó aplicándose en la posguerra y prácticamente hasta principios de los años sesenta, con la salvedad de contar con la aprobación posterior de un arquitecto. Perianes, que había trabajado para Ángel Pérez en el proyecto del Cinema Morán de Malpartida de Cáceres (año I949), logró la firma de éste en proyectos como el Cine Avenida de Zorita (año I $957^{\mathrm{IO}}$ ) y, en general, su visto bueno para otras construcciones. No obstante, no le faltaron conflictos por intrusismo profesional, con arquitectos de relieve como Fernando Hurtado, con quien también había trabajado.

Una de las primeras intervenciones del aparejador relativa a la transformación de un espacio preexistente en cinematógrafo es la de del Cine Avenida de Acehúche (I948); se trata de una propuesta que, por consiguiente, no es de nueva planta, como sí sucede en su primer diseño en Zarza la Mayor, su lugar de procedencia. El inmueble de Acehúche existía previamente como salón de baile, y su exterior apenas será transformado. De ahí que la reforma no resulte todo lo singular que es la de Zarza la Mayor, aunque pronto Perianes considerará que cualquier intervención afecta al conjunto del edificio, adquiriendo así cierta voluntad de emprender actuaciones de mayor calado y atrevimiento, que se hacen más perceptibles en ámbitos rurales y de arquitectura popular. Algo parcialmente semejante a la reforma de Acehúche sucederá con el Cine Seco, de Vegaviana, centro social diseñado por el arquitecto José Luis Fernández del Amo en el conjunto de un poblado de colonización, que Perianes apenas remodela para convertirlo en sala de proyecciones con el añadido de la cabina; por descontado, el caso de Vegaviana es diferente y la propuesta de Fernández del Amo eludía cualquier intervención externa, si bien, desafortunadamente, con el paso de los años el local originario se ha terminado perdiendo.

En el citado caso de Acehúche, el resultado era, en verdad, poco atractivo en virtud de su marcada horizontalidad, acorde tanto a las alturas constructivas de la población como al lugar, en la zona de paso de la carretera en paralelo, en que se ubica y que da nombre al inmueble, si bien, la denominación Avenida es bastante común como nombre de cines ${ }^{\text {II }}$. Pero su funcionamiento constituyó a este respecto un foco urbanístico para la población, que proyecta el incipiente sector servicios (transportes, talleres, almacenes, etcétera) de posguerra hacia la carretera, aunque actualmente el edificio se encuentra en ruinas.

10. Vid. García-Manso, Angélica: «Arquitectura de ocio en Extremadura: El Cine Avenida de Zorita», Norba-Arte, 31, 2011, pp. 165-179.

11. García-Manso, 2011, cit. [p. 166; nota 6]. 


\section{EL CORPUS DE CINEMATÓGRAFOS DE FERNANDO PERIANES: HACIA UN MÉTODO CONTRASTIVO}

Tres son, por consiguiente, las líneas de trabajo e intervención de Fernando Perianes: la certificación de obras, la reforma de inmuebles preexistentes y, finalmente, la elaboración de proyectos nuevos. En numerosas ocasiones los procesos se solapan, pues existen reformas de una envergadura tal que prácticamente representan proyectos ex novo y proyectos propiamente de nueva planta que se hacen pasar por reformas al tiempo que son certificadas, o se logra a posteriori el visto bueno de arquitectos con los que colabora el aparejador. De esta manera, una primera dificultad del corpus reside en delimitar el trabajo real de Perianes como diseñador o proyectista.

Ello implica que la documentación administrativa, en el caso de que ésta exista o se conserve, no resulte del todo fiable. El mismo Perianes certifica el final de una obra o reforma dentro de su labor profesional; pero lo llamativo del caso es que el responsable de la intervención puede ser él mismo. Resulta por consiguiente un trabajo complejo y, sobre todo, expuesto a errores de índole diferente la elaboración del corpus de edificios en cuyo diseño intervino; no obstante, el interés por conocer tal corpus radica en el carácter llamativamente singular de sus diseños. El análisis de los edificios se convierte de esta manera en un argumento importante a la hora de constatar el papel del aparejador objeto de análisis como creador de espacios que van más allá de su función comercial, para convertirse en iconos urbanos e imágenes de la memoria de una comunidad. De cualquier forma, ciertamente en el estado actual de los conocimientos y la documentación, el resultado del corpus que se ofrece es abierto.

Tres son, también y de forma subsidiaria, los frentes metodológicos mediante los que se puede efectuar una aproximación a la singular obra de Fernando Perianes: en primer lugar, la tipología de los informes (sean éstos proyectos, memorias, certificaciones, etcétera); en segundo lugar, la constatación de la existencia de inmuebles que funcionan como cinematógrafos en el eje de mitad de siglo o, de no ser así, la constatación de que se trata de edificios de nueva construcción; y, en tercer lugar, la documentación visual acerca de la existencia o no de locales de proyección con anterioridad a la ejecución llevada a cabo por el aparejador.

Así, en lo que al primer frente se refiere, la documentación conservada en el Archivo Histórico Provincial de Cáceres ${ }^{12}$, con diferentes informes rubricados por Fernando Perianes, y tal como se ha analizado ya en relación con el Cine Avenida de Zorita ${ }^{13}$, responde a trámites de certificación, a legalizaciones de intervenciones y a expedientes que se encuentran a medio camino entre la certificación y la memoria de fin de obra propiamente dicha. De algunos de tales documentos nos haremos eco en las próximas páginas.

12. Cf. Paredes Pérez, María Montaña: «Fuentes documentales para el estudio del cine en Cáceres», Balduque, 7, 2015, pp. 144-162.

13. Vid. García-Manso, 2011, cit. 
En cuanto a la constatación de existencia de cinematógrafos, existe un material bibliográfico fundamental, del que nos interesa destacar la Guía de Cáceres y provincia de Julio Rosa Roque ${ }^{\mathrm{I}}$, a caballo entre la «guía comercial»-de la empresa de transportes del editor responsable-, las referencias institucionales y, finalmente, una «guía telefónica» donde se ofrece un útil y detallado retrato de los locales en funcionamiento en I950. Ciertamente, la existencia de «salones de baile» con uso compartido como salas de proyección y de salones de baile que han sido adaptados a cinematógrafos podría complicar el reconocimiento del inmueble; no es así cuando se aportan los nombres de los propietarios o gestores y, sobre todo, cuando las localidades carecen de cine. Frente a los «anuarios» de índole nacional que documentan la industria cinematográfica, con un marcado carácter profesional, caso del Anuario Cinematográfico Hispanoamericano (el cual, además, se editó también en el mismo año I950) $)^{15}$, el volumen de Rosa Roque se ofrece como un mapa bastante detallado acerca de la difusión de los cinematógrafos en torno a la mitad del siglo XX y se hace población a población, como una herramienta que establece los límites del trabajo de Perianes.

Finalmente, el acceso público -mediante la red de internet, en: www. ideextremadura.com - a la malla de ortofotografías del denominado «vuelo de I945-I946 ${ }^{16}$ ha aportado una documentación esencial sobre la existencia o no de inmuebles construidos expresamente como cinematógrafos, toda vez que habitualmente se manejaban las ortofotos u ortofotografías de diez años después, en plena recuperación económica y con el ocio cinematográfico en pleno apogeo en el ámbito rural. Pues bien, las ortofotografías del mencionado vuelo muestran sin duda si existían o no edificios, de tal forma que la propuesta de Perianes, a pesar de que no cuenta con titulación para ello, se puede considerar como proyecto exclusivamente suyo, aunque a posteriori, según hemos apuntado, obtenga la firma de arquitectos próximos por trabajar con ellos o por mantener una relación institucional -fundamentalmente en el Ayuntamiento y la Diputación de Cáceres-.

La suma de las tres variantes permite una aproximación bastante certera a la labor del aparejador objeto de estudio como responsable de las intervenciones urbanísticas y estéticas que modernizan, a través de los nuevos edificios, el mundo rural, en ocasiones con inmuebles de enorme logro arquitectónico como es el caso del Ideal Cinema de Ceclavín, por citar un ejemplo señero de su papel como creador. A las consideraciones estéticas, en fin, se pueden añadir elementos constructivos, como el uso de determinadas molduras, de soluciones compartidas entre edificios geográficamente distantes entre sí -incluso en los nombres de los cines- constituyen otros motivos de rastreo de la labor de Fernando Perianes. De fondo, subyace la idea

14. Rosa Roque, Julio: Guía de Cáceres y provincia. Cáceres, a expensas del autor, 1951.

15. Anuario Cinematográfico Hispanoamericano. Madrid, Servicio de Estadística del Sindicato Nacional del Espectáculo, 1950.

16. Pérez Álvarez, Juan Antonio, Bascón Arroyo, Francisco Manuel, Crespo Pérez, Francisco Javier \& Charro Lobato, Cristina: «Project Casey Jones, 1945-46: el vuelo histórico fotogramétrico de la serie A en España y sus aplicaciones cartográficas», Mapping, 159, 2013, pp. 14-25. 
de imbricar una lectura de las formas arquitectónicas relacionadas con su entorno más inmediato, con el espacio urbano al que los edificios van destinados ${ }^{17}$.

\title{
3. EL EJEMPLO DEL CINE MENDO (CORIA) COMO MODELO DE DOCUMENTACIÓN
}

De la imbricación de los tres papeles del aparejador que se han señalado (certificación, reforma y diseño nuevo) y de los tres métodos propuestos (archivo administrativo; documentación -de índole hemerográfica, bibliográfica y fotográfica-; y, finalmente, la ortofotografía aérea ${ }^{18}$ ) puede surgir una percepción coherente de la importancia de las intervenciones arquitectónicas de Fernando Perianes en los edificios de ocio de la provincia de Cáceres y de su trascendencia estética y urbanística.

Un caso significativo puede estar encarnado en el proyecto de reforma del Cine Mendo, en Coria, fechado en I95I (Archivo Histórico Provincial de Cáceres, Sección Gobierno Civil $390^{\mathrm{I} 9}$ ). Se trata de un inmueble actualmente desaparecido, que estuvo situado en La Corredera de Coria, en un lugar destacable por su relación con la muralla y su proximidad a una de las avenidas principales y a los accesos al centro. El Cine Mendo se había inaugurado en 1927 con el nombre de «Cinema Mendo», destacando en su momento por tratarse del primer inmueble digno como sala teatral y de proyecciones en el entorno comarcal, y, por consiguiente, como forma de reivindicar la modernidad. Así aparece recogido en documentos hemerográficos como la noticia del periódico Nuevo Día de i6 de febrero de 1927, bajo el título de «Inauguración del Cinema Mendo», en los siguientes términos:

\begin{abstract}
«Gracias a la actividad y espíritu emprendedor de don Hilario Mendo, Coria cuenta ya con un local suficiente para toda clase de espectáculos teatrales. El Cinema Mendo viene a llenar en esta ciudad el vacío más grande, no solo de la ciudad, sino de la zona comarcana. Es el primer teatro que se construye en este conglomerado de pueblos que son Portaje, Moraleja, Casillas y otros. Hasta ahora no había para expansiones del espíritu más que unos malos locales a los que se llamaba pomposamente salones de baile y que ni para bailar servían. Ahora hay un teatro, sin pretensiones, pero completo. De escenario amplio, de sala espaciosa, cómoda, bien iluminada, ornamentada sencillamente, pero con gusto. Un teatro capaz para mil personas, lo que ya es suficiente para esta región. Coria, con esta obra del señor Mendo, ha dado el mismo importante paso que Cáceres con la construcción de su Gran Teatro.»
\end{abstract}

En el texto del periódico se descubre la transcendencia que se concede a la importancia sociológica del inmueble: primero en la ciudad y la comarca, que ocupa

17. Con derivaciones como las que ha llevado a cabo Juan Antonio Ramírez en sus estudios sobre las arquitecturas de ocio, y, por supuesto, sobre las salas de cine. Cf. RAmírez, Juan Antonio: «Especie en extinción: de las grandes salas cinematográficas a los multicines», Arquitectura Viva, 60, 1998, p. 112.

18. Cf. Virgós Soriano, Luis Ignacio \& García CePedA, Francisco: «La ortofotografía y la cartografía catastral», Catastro, 83, 2015, pp. 7-30.

19. En adelante AHPCC-GC. 
un papel equivalente al del Gran Teatro de la capital cacereña -inmueble que había sido inaugurado apenas unos meses antes ${ }^{20}-\mathrm{y}$, a pesar de no destacar por su elegancia arquitectónica («teatro sin pretensiones» con sala «ornamentada sencillamente»), posee el espacio y el aforo precisos para el ocio del siglo XX.

Un cuarto de siglo después, en I95I, el edificio será remozado. La arquitectura precedente ahora se percibirá como falta de comodidad y carente de estética moderna. Así lo refiere Fernando Perianes en la «Memoria» de intervención sobre el inmueble para destinarlo de forma predominante y casi exclusiva a sala de proyecciones.

En el texto de la documentación administrativa para la reforma redactado por el aparejador se destacan los aspectos fundamentales de las intervenciones que Perianes promueve, de unos cambios que pretenden dotar de un aspecto y una función nuevas al espacio. El diseño casi en exclusiva como cine supone la ampliación del aforo de la sala de butacas con la eliminación de parte del escenario teatral y con los cambios estructurales que ello implica; pero, tal como el mismo Perianes anuncia, también cambios «estéticos», que, sin embargo, no precisa, aunque sin duda tales cambios afectan también a la fachada, es decir, a la reivindicación urbana del edificio en unos momentos en los que existen otras salas de proyecciones en la población en competencia con el Cinema Mendo.

Los cambios en la fachada son difíciles de dilucidar ante la ausencia de documentos fotográficos conocidos con anterioridad a la reforma. No obstante, además de encontrar en las sombras de las ortofotografías variaciones de tono que implican hipotéticas alteraciones volumétricas -importantes para destacar la envergadura de las variaciones del proyecto, aunque es obvio que el edificio ya existía-, tales cambios se pueden apoyar también en paralelismos de índole estética. En efecto, según veremos, el arco rebajado con reborde en la fachada coincide en su diseño con la propuesta que Perianes para el Cine España de Albalá hace en el mismo año I95I, al tiempo que recuerda de manera general el diseño de la fachada del cine Roel/ Mari-Emi de Piedras Albas; a su vez, la celosía de mampostería que funciona como elemento central coincide con propuestas concomitantes como el Cine España de Torrejoncillo o el Cine Salamanca de Deleitosa, según se expondrá. Se trata de dos motivos combinados que reflejan la intervención de Perianes sobre una fachada que, probablemente, se presentara anteriormente con una estética distinta a la propugnada por el aparejador.

De cualquier forma, una de las premisas estéticas que fundamentan nuestro estudio es el de la implicación de los diseños de Perianes con motivos próximos al entorno del edificio. Así, la fachada del Cine Mendo resulta, a primera vista, neutra, limitándose a confirmar que se trata del acceso a un cinematógrafo. Hay, empero, elementos que no son azarosos: es el caso de las ventanas del piso que poseen un frontón triangular en su moldura; o la misma celosía de mampostería, cuyo lado superior replica el arco escarzano del frontón de la fachada, configurando así una concentración de la mirada hacia la celosía central y, por ello, confiriéndose al

20. Vid. Narganes Robas, David \& Jiménez Berrocal, Fernando: El teatro en Cáceres. Archivosy documentación (1586-1926). Mérida, Junta de Extremadura, 2009. 
conjunto un aspecto de retablo, en el que los rebordes de las ventanas superiores también actúan junto con la celosía como vanos en el conjunto de la fachada. No se trata de una asociación casual si se contrapone el conjunto con la hornacina de la Virgen de Argeme en el retablo de su ermita, cuya fachada isósceles resulta concomitante con los frontones moldurados de las ventanas.
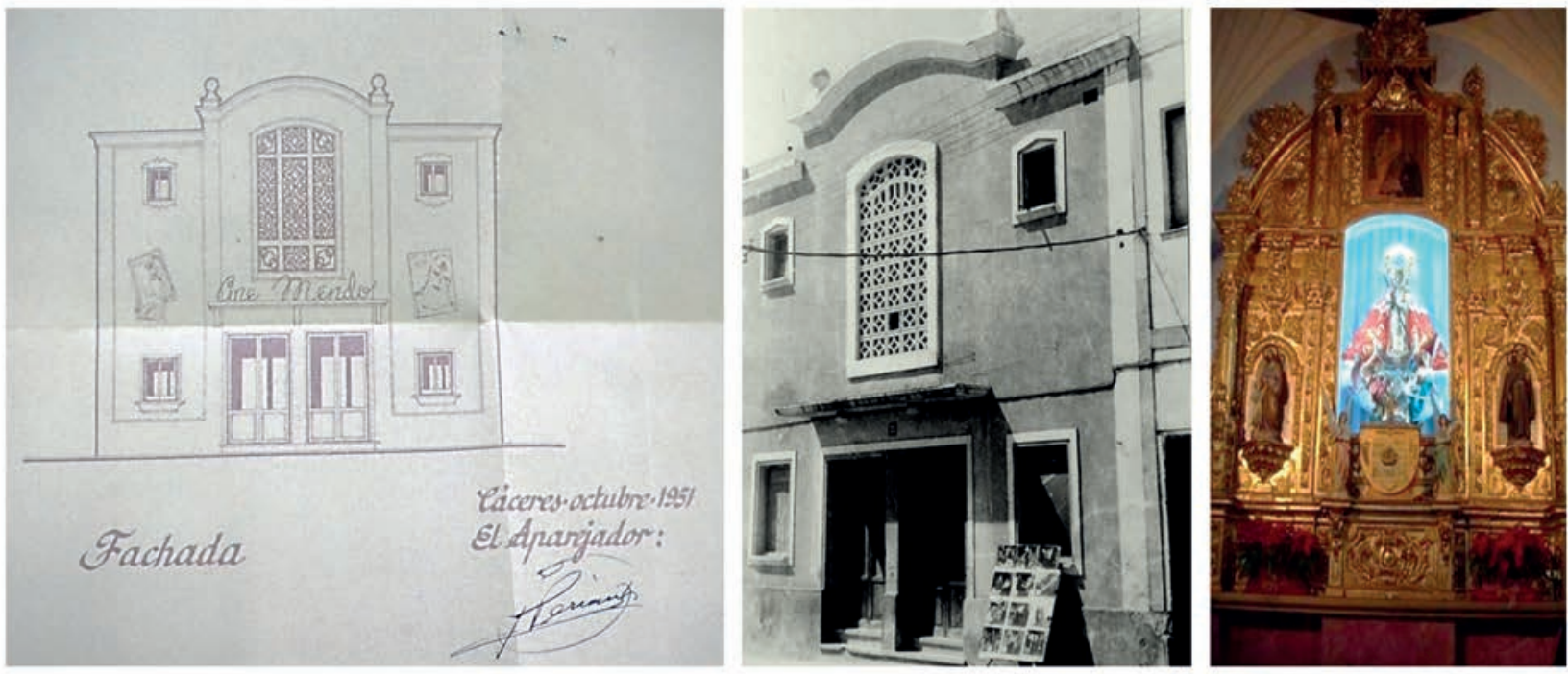

FIGURA. 1. CORIA. ALZADO DEL CINE MENDO: ARCHIVO HISTÓRICO PROVINCIAL DE CÁCERES (AHPCC), FONDO GOBIERNO CIVIL (GC), AHPCC-GC.390; FACHADA DEL CINE MENDO Y RETABLO DE LA ERMITA DE LA VIRGEN DE ARGEME (CORIA). Fotografías sin copyright conocido.

\section{CORPUS DE CINEMATÓGRAFOS}

\subsection{ALBALÁ. CINE ESPAÑA}

Fernando Perianes trabaja casi simultáneamente a la reforma del Cine Mendo de Coria en el proyecto del Cine España de Albalá, encargo de la familia Barrantes; se trata del primer cinematógrafo estable de la población, que casi una década después, en el año I960, contará con un segundo local para proyecciones, el Cine Dolores, diseño del arquitecto Joaquín Silos Millán ${ }^{21}$. El cinematógrafo comienza su andadura a principios del año I95I, y el edificio refleja ya el dominio formal con el que aborda el aparejador sus trabajos. De cualquier manera, en lo formal, al margen de repetir la cornisa alabeada del Cine Mendo, el Cine España revela bien a las claras el magisterio del arquitecto municipal cacereño Ángel Pérez, pues en tanto la disposición de la fachada recuerda la del Cinema Morán de Malpartida de Cáceres, el azul patinado como pintura exterior responde a la impronta del Cine

21. Vid. García-Manso, Angélica: «Didáctica del patrimonio: El Cine Wetonia y otros edificios de ocio de Joaquín Silos Millán», Norba-Arte, 37, 2017, pp. 261-277. 
Norba de la capital cacereña. El edificio posee una enorme estilización, realmente lograda en una población que carece de monumentos de relieve que le sirvan de referencia, pues ni siquiera la Iglesia de la Magdalena por sí misma confiere identidad iconográfica a la localidad. De ahí que, en principio, la influencia estética de Ángel Pérez resulte la más inmediata y evidente.

El inmueble no deja de evocar la casa consistorial del pueblo -cuya reforma en el siglo XX no hemos podido documentar, aunque entre la producción de Fernando Perianes no faltan proyectos para la administración municipal, siendo su obra más lograda la del ayuntamiento de Jaraíz de la Vera, edificio en el que se replica en cierta forma el de la ciudad de Cáceres-. En efecto, a pesar de su inspiración a caballo entre la arquitectura tradicional y la evocación de soportales, la tríada de arcos de herencia decimonónica del Ayuntamiento de Albalá y el reborde moldurado de las ventanas de la balconada que lo preside coinciden con la disposición y rebordes presentes en la fachada del Cine España. Se trata de unas molduras que se descubren en edificios en los que ha trabajado Perianes, como la modernista Casa de los Iglesias en Cáceres, diseñada inicialmente por el arquitecto Ángel Pérez y sobre el que años después también intervendrá el aparejador, la reforma del Cine España de Aliseda o, por poner otro ejemplo cercano a Albalá, las ventanas hacia la plaza del Cine Colorina de Valdefuentes.
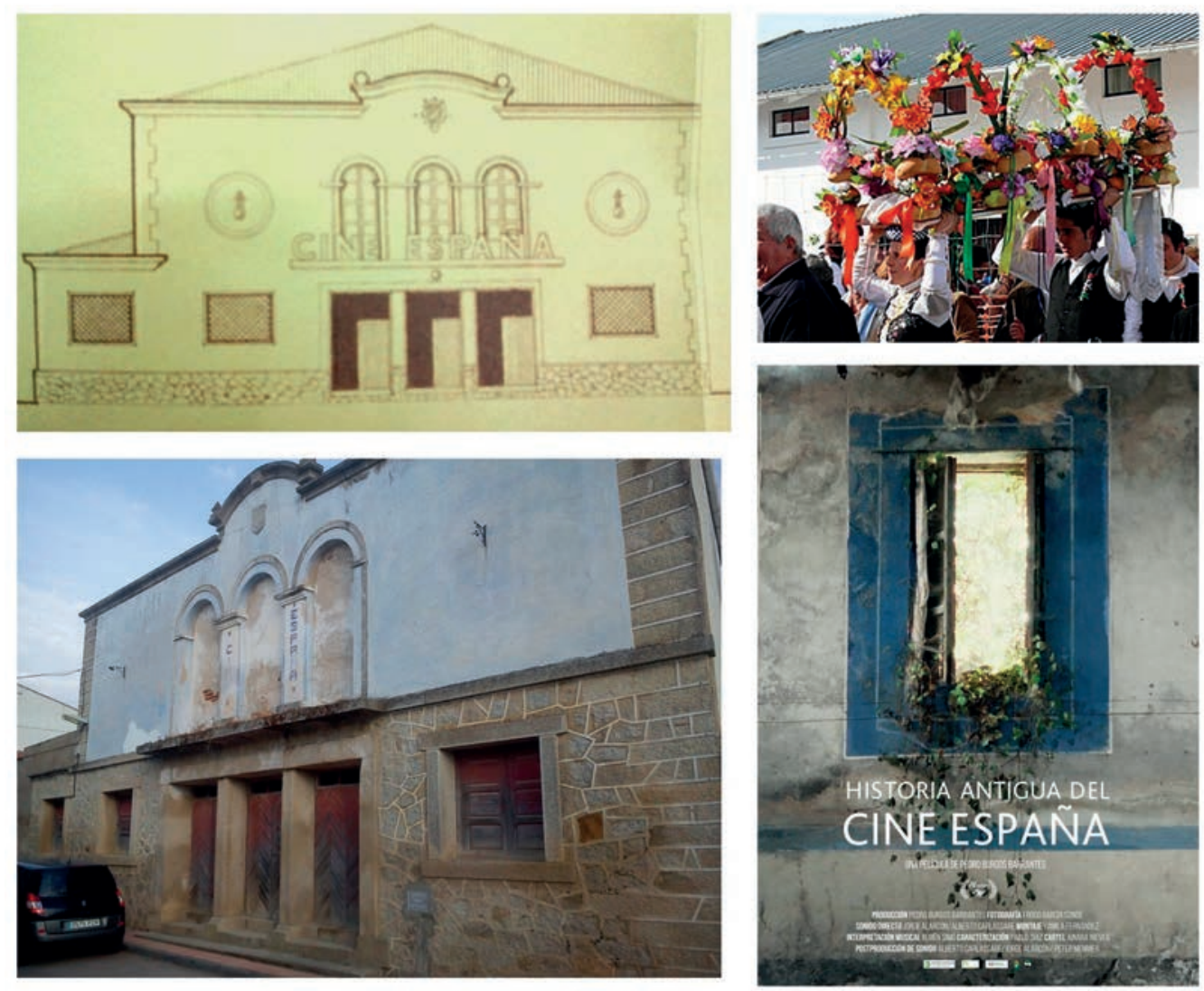

FIGURA 2. ALBALÁ. ARCHIVO HISTÓRICO PROVINCIAL DE CÁCERES (AHPCC), FONDO GOBIERNO CIVIL (GC): AHPCC-GC.87. Fotografías de la autora y cartel del filme de Pedro Burgos (2007). 
La documentación administrativa relativa al edificio a la que hemos tenido acceso es escasa (AHPCC-GC.87), limitada a una breve certificación de final de obra que data del mes de febrero de I95I, sin Memoria propiamente dicha, aunque sí se aportan los alzados y planos - diez años después, en I96I, Perianes presenta la Memoria del Cine de Verano anexo, donde se detallan elementos del Cine de Invierno que se comparten entre sendos espacios y en 1963 se hace otro tanto con una sala de fiestas también anexa-, en el que se hacen visibles los llamativos elementos decorativos esbozados por Perianes: zócalo, balcones ciegos, medallones portalámparas y un escudo con el motivo de una banda, como una lira musical labrada en diagonal en el edificio construido.

El edificio se encuentra actualmente sin uso; si bien, al menos, ha merecido la atención cinematográfica a través de un documental, producido en el año 2017 y dirigido por un descendiente del fundador del Cine. Se trata del filme Historia antigua del Cine España, de Pedro Burgos Barrantes (Fig. 2).

\subsection{ALDEACENTENERA. CINE SALAMANCA}

El Cine Salamanca de Aldeacentenera se yergue a la entrada de la población, en una curva de la carretera por la que se accede a ésta y que la conecta con la autovía A-5 (además de con la antigua carretera nacional $\mathrm{N}-5$ ). El lugar es significativo no sólo por no pertenecer al centro urbano, sino por ser a mediados del siglo XX marco de un área de expansión asociada a la vía de acceso al pueblo, sirviendo el inmueble así, de paso, como carta de presentación: en efecto, el cinematógrafo es el primer edificio que se aprecia, el cual además resulta singular por la importancia que se concede en el momento de su construcción al ocio encarnado en el Séptimo Arte y por la estética modernizadora que aporta al entorno. De cualquier forma, el inmueble se sitúa en una zona orográfica en leve bajada, de forma que la sala en sí se presenta hundida respecto a la altura de la calzada, si bien tal disposición no impide su condición relevante; más bien al contrario, anuncia la pendiente de descenso hacia la zona central de la población.

La comparación entre las ortofotografías del vuelo de I945-1946 y las del de I956I957 revela que se trata de un inmueble de nueva edificación. De hecho, se trata de uno de los edificios más grandes de la localidad en el momento de su erección. No se conserva que sepamos memoria del proyecto, únicamente los planos elaborados por el aparejador (AHPCC-GC.88). No obstante, existen diferentes elementos que involucran el diseño con la personalidad de Fernando Perianes: desde el nombre del cinematógrafo, que coincide con el de Zarza la Mayor -aunque también con el de un cine madrileño-, hasta la propuesta del elemento de la celosía de ladrillo que coincide con la que se propugna para el Cine España de Torrejoncillo.

Ahora bien, la -por así decir- «poética» de Perianes de incardinar sus propuestas con el entorno es la que llama más la atención al respecto de un edificio muy elaborado, consistente en un juego de volúmenes adosados, una fachada corrida y con dos frentes, mostrando especie de torres truncadas, arcos en vanos que llegan al dintel, con franjas de ventanas enmarcadas, etcétera, que lo convierten en 
una estructura poliédrica. ¿Qué puede haber inspirado al aparejador a la hora de organizar visualmente así el edificio? Ciertamente, al igual que hemos señalado a propósito de Albalá, la población de Aldeacentenera carece de un monumento icónico que actúe como un identificador del lugar. No obstante, la plaza presenta una llamativa disposición arquitectónica al presentar adosados iglesia y ayuntamiento, en un continuo roto por una torre del reloj que parece compartida entre ambos edificios y un campanario, en el flanco de la iglesia, que no deja de ofrecer cierto aspecto de torreón defensivo. Bien es cierto que, en origen, la arquitectura de la Casa Consistorial se inscribía en el estilo rural o popular y que la secuencia con la iglesia no llamaba tanto la atención como en renovaciones posteriores. Y es que la propia fachada de la iglesia aparecía enfoscada en blanco al igual que el edificio administrativo, con la intercalación entre ambos y en la esquina del templo de la torre del reloj y del campanario, de piedra vista. El conjunto posee un enorme dinamismo visual, de continuidad de volúmenes, que Perianes repite en el cinematógrafo. Se trata, en fin, de un edificio que, sin renunciar a hitos verticales, posee una marcada horizontalidad, tal como se produce también en el Cine Maldonado de Cañamero.
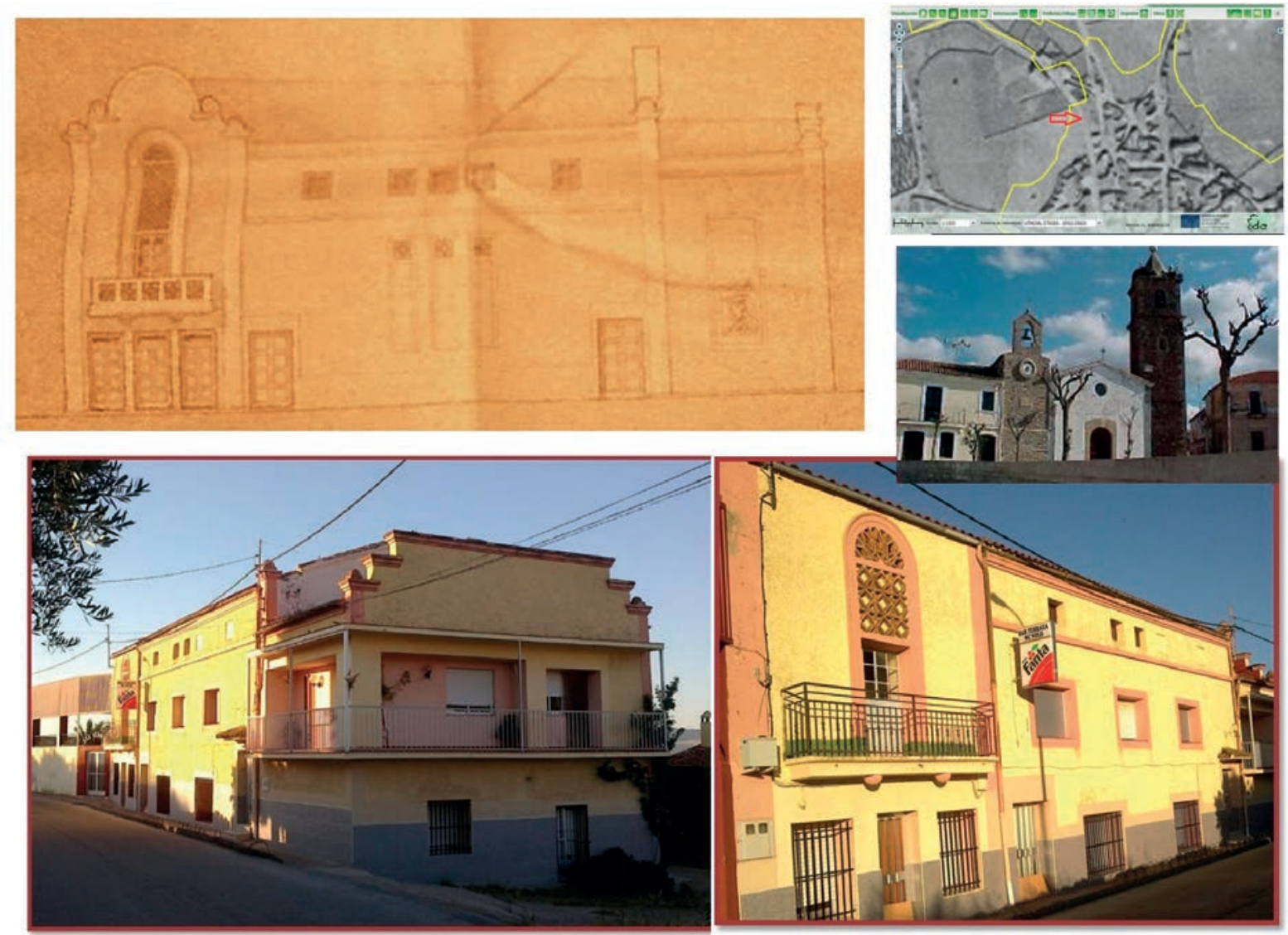

FIGURA 3. ALCEACENTENERA. VUELO DE 1945-46. IDEEX (INFRAESTRUCTURA DE DATOS ESPACIALES DE EXTREMADURA), JUNTA DE EXTREMADURA. ARCHIVO HISTÓRICO PROVINCIAL DE CÁCERES (AHPCC), FONDO GOBIERNO CIVIL (GC): AHPCC-GC.88. Fotografías de la autora y fotografía de las fachadas antiguas de la Casa Consistorial y la Iglesia de San Bartolomé de Aldeacentenera, sin copyright conocido. 
La celosía de la torre de la izquierda constituye uno de los elementos decorativos más significativos, no sólo para ubicar uno de los accesos, sino, como hemos indiciado, por remitir a la del Cine España de Torrejoncillo, una de las soluciones estéticas más logradas por parte de Perianes, según analizaremos más adelante. De acuerdo con tales premisas, el propósito de Perianes parece ser el de diversificar los volúmenes de un edificio donde acceso lateral y sala de proyecciones se encontraban en distintas alturas; $y$, de paso, ofrecer una falsa fachada hacia la población, aprovechando el escalamiento que ofrece el desnivel frente a la altura de la calzada. En fin, en la actualidad, más que probablemente se haya perdido parte de la decoración exterior más expuesta a las inclemencias meteorológicas dado que el arco de la celosía prácticamente roza a ras con el nivel del techo actual, reformado el inmueble como bar y como vivienda, con una nueva balconada a la derecha en su altura de la calle (Fig. 3).

\subsection{ALISEDA. CINE ESPAÑA}

En el Cine España de Aliseda, al igual que sucederá de forma más evidente con el homónimo Cine España de Torrejoncillo, Perianes interviene sobre un edificio que ha sido tradicionalmente utilizado con anterioridad como centro de ocio, desde los años 20 del pasado siglo, y que, por circunstancias del deterioro por el paso de los años o, probablemente, por un incendio, es reformado y adaptado arquitectónicamente con primacía como sala de proyecciones, tal y como estaba en realidad ya funcionando en la década de los años 30 con el nombre de «Teatro Cine España». Una de las peculiaridades del edificio se encuentra en su enclave: la fachada forma esquina entre una calle de enorme inclinación (actual Travesía Calvario; antes Calle Cura Tomás Pizarro) y, tangencialmente, una vía de paso de mayor importancia en la parte más baja, en una zona de tránsito de la población (actual Calle Luis Chamizo), calle sobre la que se extendía el Cine de Verano anexo, cuyo espacio ha desaparecido parcialmente a día de hoy. El inmueble se restaura en I95I y ofrece un volumen compacto, como emergiendo del suelo, si bien su línea predominante será la horizontal, semejante a un peldaño en el desnivel de la calle. El industrial Heliodoro Godoy es el gestor más importante en el proceso de renovación. El archivo particular de la Familia Godoy conserva los planos firmados por Perianes, además de otros testimonios relacionados con la historia de las proyecciones de filmes en el cinematógrafo.

Se trata de un edificio de remarcable interés estético por la combinación de motivos curvos (dos arcos ciegos y dos ventanas geminadas enlazadas por arcos ligados) y rectos (la gruesa cornisa) en plena yuxtaposición, que culmina en el acabado ondulado del muro del Cine de Verano en lo que concierne a la Calle Luis Chamizo. La propuesta resulta fuertemente compacta al integrar elementos curvos decorativos bajo la cornisa recta y sobre el dintel de la puerta; también refleja cierta idea de puzzle al organizar la fachada en lienzos separados mediante columnas lisas encastradas en el nivel superior, resolviéndose el nivel inferior, que se acorta conforme el desnivel se pronuncia, a la manera de zócalo, y siendo la columna que 
actúa de gozne la más elaborada, al coronarse en la parte del dintel con un círculo decorativo dispuesto en chaflán. Las molduras de los arcos responden al modelo habitual de los rebordes que emplea en sus intervenciones Perianes. Finalmente, los colores que se combinan originariamente eran los de la bandera de España, conforme al nombre del cinematógrafo, que aparecía bajo el primer arco ciego rebordado.

$\mathrm{Al}$ cabo, la integración de la arquitectura tradicional del inmueble originario con las soluciones de funcionamiento y decorativas a las que recurre el aparejador deriva en un edificio original, que destaca en su entorno y se convierte en polo urbanístico de la zona del pueblo que se acerca a las laderas de la prácticamente colindante elevación del Pericuto en la Sierra de San Pedro, cuyo desnivel es el de la misma calle en la que parece afirmarse horizontalmente el Cine España. Por lo demás, el resultado deviene de inspiración historicista, aunque sea en sus elementos más esquemáticos, como las molduras, la geminación de ventanas, el grueso dintel, las columnas lisas encastradas, etcétera, tal como, por ejemplo, se aprecia en el edificio Casa de los Iglesias, en Cáceres, según proyecto de Ángel Pérez y cuyo interior remodelará lustros después Perianes. El edificio no está actualmente -que sepamos- en uso y puede estar sometido a un deterioro estructural que invita a su conservación (Fig. 4).
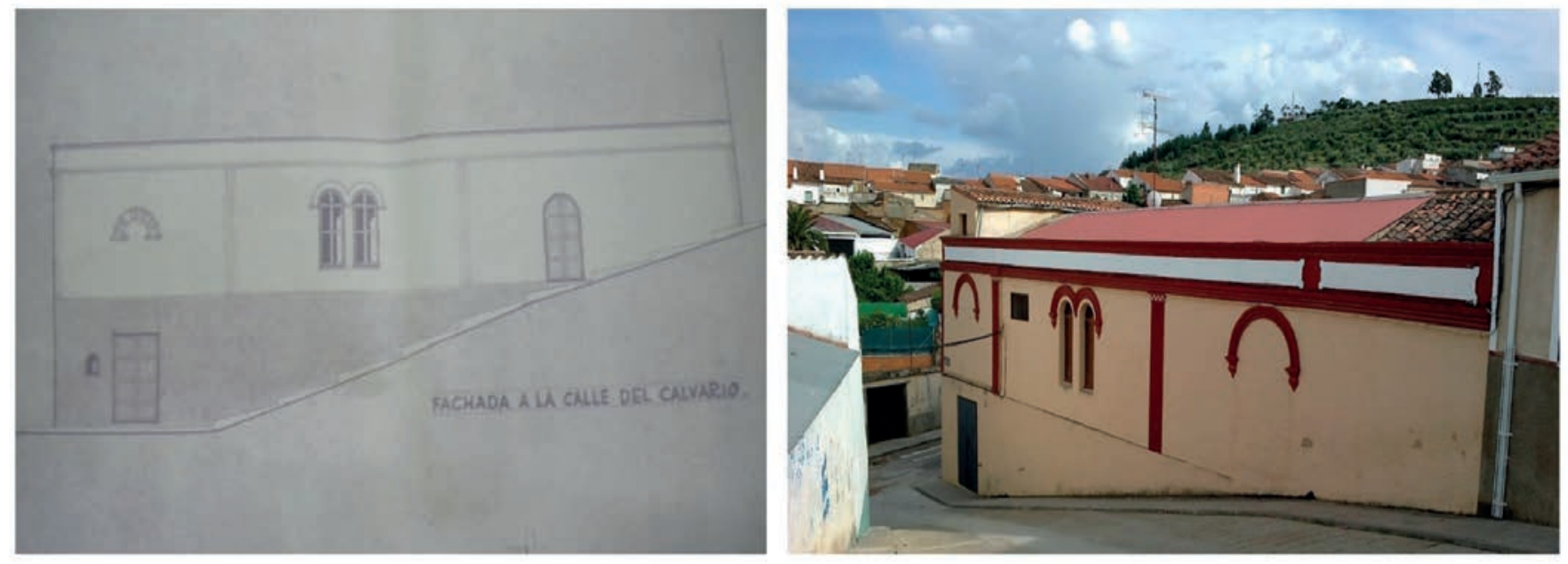

FIGURA 4. ALISEDA. ARCHIVO DE LA FAMILIA DE HELIODORO GODOY. Fotografía de la autora.

\subsection{CAÑAMERO. CINE MALDONADO}

El Cine Maldonado de Cañamero se encuentra en una calle intermedia entre la carretera nacional que atraviesa hoy en día la población y el centro propiamente dicho, con sus sedes administrativas, comerciales y religiosas. El inmueble recorre la actual calle José Fernández, en aquel momento casi a las afueras de la localidad, y próxima a uno de los accesos que conectan la carretera con el núcleo urbano. El edificio posee una marcada horizontalidad, con la sala de proyección en paralelo a la calle, aunque el volumen edificado en plano es triangular. La horizontalidad provoca que la fachada aparezca corrida sobre la calle, $y$, al igual que sucede con el Cine Salamanca de Aldeacentenera, se organice como una sucesión de volúmenes 
en horizontal, si bien con formas más rectas que las de Aldeacentenera, aunque con una diferencia sustancial: en tanto el Cine Salamanca responde a una construcción aislada, el Cine de Cañamero se inscribe en el espacio urbano de una calle en una manzana de perímetro irregular. El edificio es de los de construcción más reciente, pues no aparece en las ortofotografías de los vuelos de los años cuarenta ni en las de los cincuenta, en un espacio en aquel momento exterior al núcleo urbano y pronto una zona de expansión de la población. La escueta memoria que redacta Perianes está fechada en el año I96I (AHPCC-GC.I33).

La horizontalidad y, al tiempo, el saliente de las cornisas, balcones y los volúmenes emergentes así como la geometría recta de las ventanas confiere al edificio un aspecto de puzzle (idea que hemos planteado ya en torno al cine de Aliseda), a partir de piezas en las que la variación es el elemento básico: distintas alturas, moldes rectos o de arcos rebajados en puertas y ventanas, balconadas de tipologías diferentes, con distintos niveles de profundidad, etcétera, todo lo cual otorga un enorme relieve al inmueble a base de oquedades y lienzos prominentes. El carácter rectilíneo aleja la propuesta de la arquitectura tradicional, para dar cabida a un edificio que buscó en su momento ser moderno, es decir, de aspecto funcional y racionalista, aunque probablemente no haya envejecido estéticamente bien.
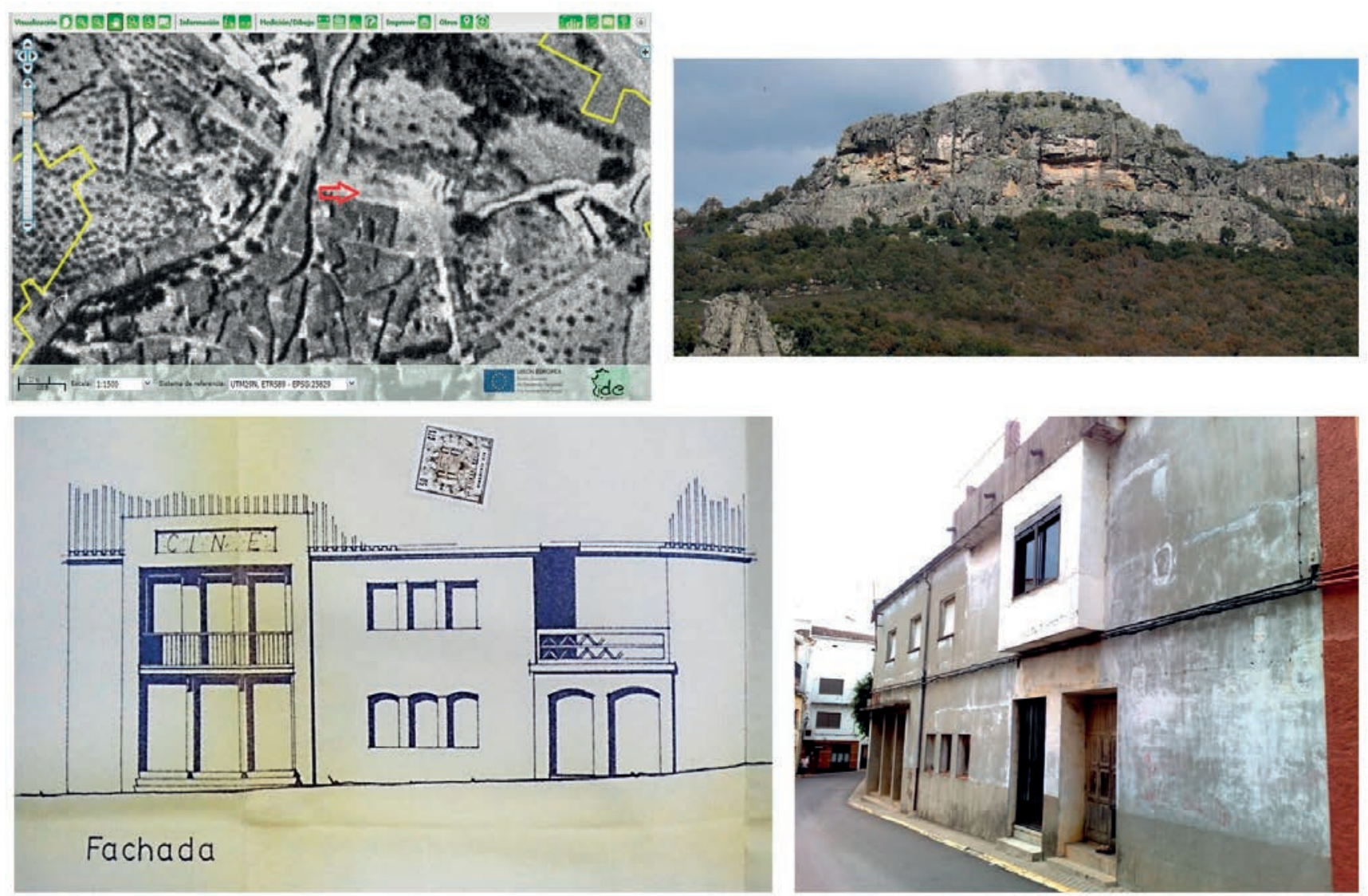

FIGURA 5. CAÑAMERO. VUELO DE 1956-57. IDEEX (INFRAESTRUCTURA DE DATOS ESPACIALES DE EXTREMADURA), JUNTA DE EXTREMADURA. ARCHIVO HISTÓRICO PROVINCIAL DE CÁCERES (AHPCC), FONDO GOBIERNO CIVIL (GC): AHPCC-GC.133. Fotografías de la autora. 
Pero también existe en la propuesta de Perianes cierta voluntad por así decir geológica, relativa a la imbricación del inmueble con el entorno orográfico de las Villuercas, cuyo fondo más emblemático es el Cancho del Reloj (llamado así por las pinturas rupestres que alberga), que escolta el Río Ruecas en la Sierra del Pimpollar, tratándose en buena medida de un icono de la población, a la que aporta un skyline paisajístico singular; pues bien, da la impresión de que las irregularidades de la roca se proyectan sobre el edificio como si las primeras fueran el trasfondo del Cine, y que éste replica (Fig. 5).

\subsection{CECLAVÍN. IDEAL CINEMA}

Uno de los cinematógrafos más interesantes proyectados por Fernando Perianes es el Ideal Cinema de Ceclavín, caracterizado por un elegante chaflán con arco de medio punto y ojo cegado que delimita sus dos fachadas: la de la profundidad de la nave, que adquiere forma escalonada, y la del acceso principal, orientada hacia el espacio urbano más importante. Los lienzos enmarcados de la fachada de acceso recrean una especie de pantalla apaisada en la que se inserta el nombre del cine y, en general, sus proporciones y sencillez y los colores terrosos y cálidos confieren al inmueble un lugar preeminente en el entorno en que se erige. El edificio, en fin, ofrece cierto aire «decó centroeuropeo», procedente en realidad de su inspiración en el Cine Norba de la capital de Cáceres, obra señera del arquitecto Ángel Pérez ${ }^{22}$. El inmueble ocupa un lugar importante, en la actual Avenida de Todos los Emigrantes, en plena travesía de la población, en una intersección de las carreteras hacia Acehúche (actual carretera Ex-372) y hacia Portaje (actual CC-49), creando en el cruce entre ambas una plazoleta de acceso a la población que actúa, en cierta manera -reforzada a fecha de hoy con otros elementos ornamentales-, como tarjeta de presentación de Ceclavín.

Aunque el promotor principal era el industrial local Antonio Herrero, al ser parte de sus restantes socios propietarios la familia Guillén, dueños del Cine Salamanca de Zarza la Mayor, localidad cercana de la que, además, era natural Perianes, que fue quien hizo el proyecto de dicho cine, se contó con él nuevamente para este emblemático edificio de los cinematógrafos de la provincia cacereña. Se trata, pues, de un edificio de nueva planta: las ortofotografías del vuelo de i945-I946 reflejan que aún no existía el inmueble a mediados de la década de los años cuarenta; en el vuelo de I956-I957 ya sí. El cine comenzó sus proyecciones en el año I949, cesando el otro cine de la población, que había funcionado al menos durante los diez años previos.

La embocadura del escenario-pantalla delata la influencia del diseño del edificio: se trata de un escenario en arco de medio punto cuyo referente más próximo es el del Cine Norba de la capital cacereña, construido quince años antes y obra clave, actualmente desaparecida, del arquitecto Ángel Pérez, con quien colabora Perianes en diferentes proyectos a lo largo de su vida profesional (se trata de una

22. Cf. Pérez Rojas, Francisco Javier: Art Déco en España. Madrid, Cátedra, 1990. 
embocadura que también emplea Perianes en edificios que reforma como el del Cine España de Aliseda, entre otros).

De igual forma, la propuesta del diseño exterior con un arco central menos rebajado y en chaflán que en el caso del Ideal Cinema replica de alguna manera el frente del Cine Norba. No obstante, en realidad, además de gozne, el aspecto vertical y como de torre del chaflán, con un ojo de buey ciego, remite a uno de los edificios más emblemáticos de Ceclavín, la llamada Torre del Reloj, del siglo XVI y antigua sede de la cárcel, con cuyas proporciones parece dialogar para ofrecer, según hemos dicho, en la nueva zona de acceso a la población que se está creando con la expansión de ésta hacia el este, un elegante duplicado (Fig. 6).

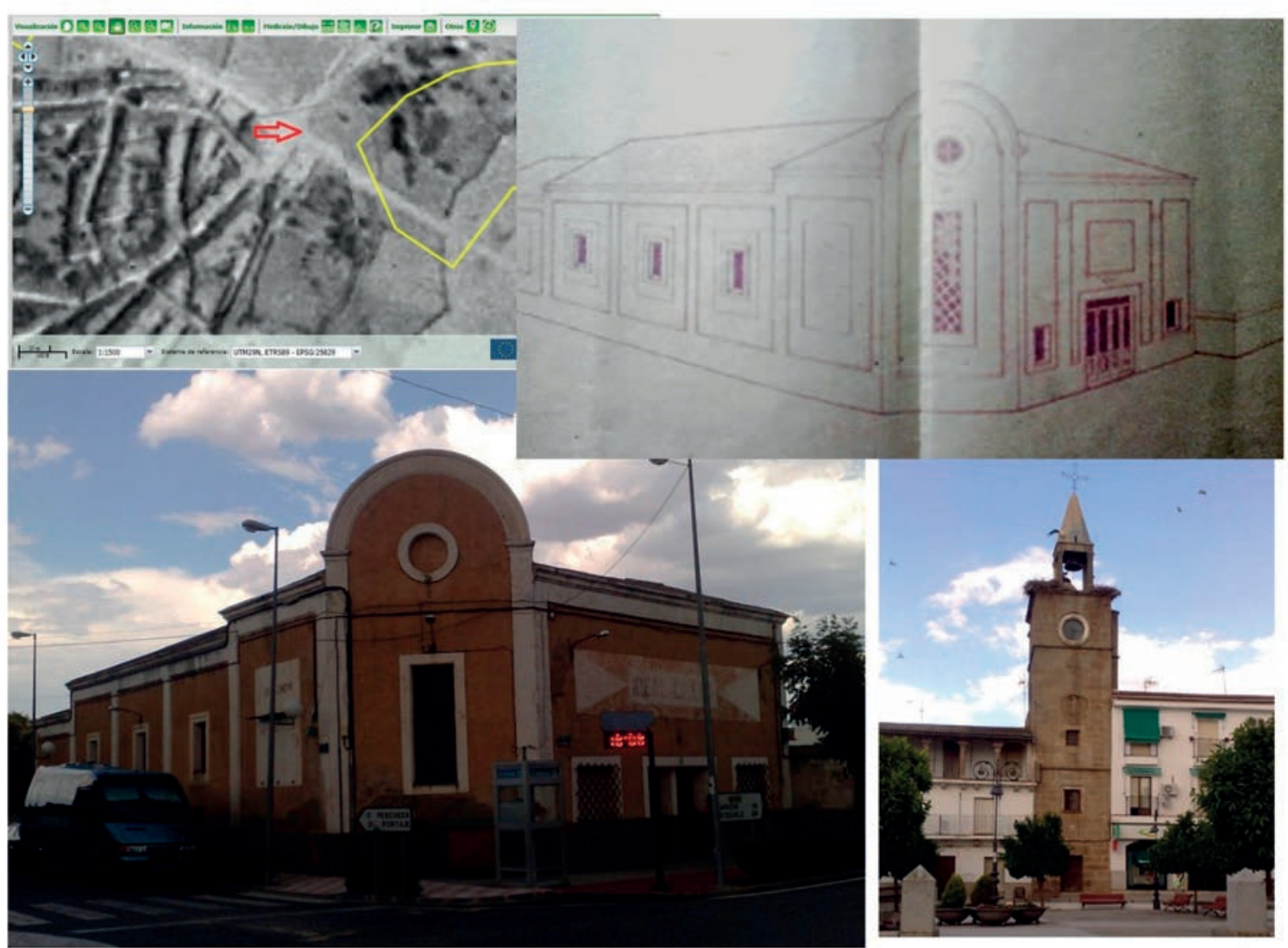

FIGURA 6. CECLAVÍN. VUELO DE 1945-46. IDEEX (INFRAESTRUCTURA DE DATOS ESPACIALES DE EXTREMADURA), JUNTA DE EXTREMADURA. ARCHIVO FAMILIAR DE TOMÁS CIVANTOS. Fotografías de la autora.

\subsection{PIEDRAS ALBAS. CINE ROEL/MARI-EMI}

El primer nombre del cine surge de la terminación del apellido de la familia propietaria Ro-El, de Villaroel o Vilaroel, y para el que incluso se idea un motivo heráldico que se ubicará en la fachada del cine (también la fachada del Cine España de Albalá se caracteriza por la presencia de un pequeño escudo, aunque con motivos más circunstanciales que los del cine de Piedras Albas, en el que sí se lee la palabra «cine»). El cine fue inaugurado en I953, como Cine Ro-El, si bien con 
posterioridad se le cambió el nombre a Cine Mari-Emi, a pesar de que no se cambió el escudo de la fachada.

La localidad de Piedras Albas es rayana, es decir, responde a un espacio fronterizo con Portugal en el que Fernando Perianes desarrolla buena parte de sus proyectos; de hecho, la población está muy próxima a Zarza la Mayor. El inmueble se fecha, según decimos, en I953, en que aparece certificado por Perianes, a partir de un proyecto de un año antes, de I952; y, en principio, es de nueva planta, pues no parece apreciarse en la ortofotografía del vuelo del año I945-I946 (sí en la posterior), si bien la imagen en lo que se refiere al vuelo citado resulta en verdad poco legible. El cinematógrafo tampoco aparece citado en la Guía de Cáceres y provincia de Julio Rosa ${ }^{23}$. Se encuentra en la actualidad junto al moderno edificio del ayuntamiento, en la Plaza de la Concordia; tangencial tanto ahora como en sus orígenes con la carretera Ex-II7.
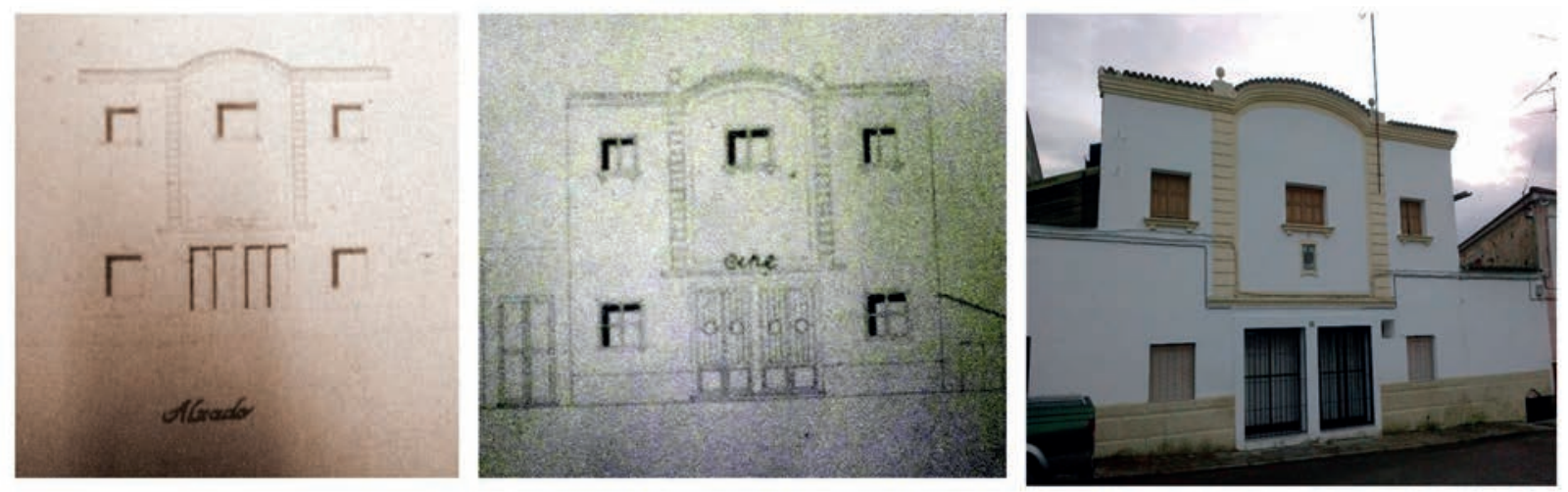

FIGURA 7. PIEDRAS ALBAS. ALZADO DE FERNANDO PERIANES Y ALZADO DE TOMAS CIVANTOS. ARCHIVO HISTÓRICO PROVINCIAL DE CÁCERES (AHPCC), FONDO GOBIERNO CIVIL (GC): AHPCC-GC.2041. Fotografía de la autora.

El edificio se caracteriza por un elegante frontal con un dintel curvo rebajado de marcada influencia portuguesa, sobre una fachada sencilla, organizada en tres lienzos en su primera planta, con rebordes verticales únicamente en dicha planta y no en la baja o de acceso, si bien el lienzo central casi desciende sobre las puertas de acceso, creando una especie de hornacina como la del Cine Mendo de Coria. Por lo demás, aunque en su proyecto Perianes no dibuja unos pináculos en los extremos del frente del lienzo central, estos aparecen en el alzado que se efectúa para la autorización del montaje eléctrico por parte de la Delegación de Industria de Cáceres, obra del perito Tomás Civantos (AHPCC-GC.204I); se trata de un indicio claro de que tal elemento decorativo constituye un añadido posterior sobre el alzado inicial de la fachada diseñado por el aparejador Perianes. Los alféizares de las ventanas también resultan característicos en la fachada, y, aunque con una orientación diferente, se presentan como propuesta a caballo entre la reforma del citado Cine Mendo de Coria y el también mencionado Cine España de Albalá.

23. RosA, 1951, cit. 
Finalmente, el logro estético fundamental de Perianes no radica exclusivamente en asimilar la influencia portuguesa para un edificio de la Raya, sino, sobre todo, en la integración del edificio sin desentonar en la arquitectura popular, como una casona señorial o solariega (de ahí la importancia del escudo, a pesar de no ser éste grande) y, al tiempo, remarcando su uso para el ocio contemporáneo: un cinematógrafo.

La peripecia del edificio ha sido variada a lo largo de los años siendo, tras la clausura del cine en I97I, un supermercado, entre otros usos. Actualmente se conserva en buen estado, aunque transformado por completo en su interior (Fig. 7).

\subsection{TORREJONCILLO. CINE ESPAÑA}

Torrejoncillo ha sido reconocida tradicionalmente como una localidad próspera en actividad comercial, industrial y también, y consiguientemente, desde una perspectiva demográfica con anterioridad a la debacle emigratoria de los años sesenta. De hecho, se trata de una de las primeras poblaciones de la provincia con proyecciones cinematográficas. Llegará a tener dos cines importantes en la década de los años cincuenta y sesenta, el Cine Lasi (el nombre procede del acrónimo de su promotor, Laureano Simón, en tanto el inmueble es diseño del arquitecto Fernando Hurtado, autor también de otros cines de envergadura, como el Cine Ana-Mary, de Alcuéscar) y el Cine España, surgido de la remodelación de un local teatral anterior, tradicional en Torrejoncillo. A estos cines hay que añadir el Cine Alvernia, de carácter parroquial, de breve aunque singular trayectoria en el conjunto de los cines parroquiales de mayor relieve, como son los de Guadalupe, Brozas o los de la misma capital cacereña ${ }^{24}$; el otro cinematógrafo nace de la remodelación de un local teatral previo.

En efecto, hasta finales de la década de los años cuarenta existió en el mismo emplazamiento en el que hoy se levanta el «Cine España» un edificio de arquitectura rural que servía como salón de baile y de espacio para otros tipos de espectáculos, entre ellos proyecciones cinematográficas. Se trataba de un local del que ya se tienen noticias en los años veinte y al que se conocía como «El Corralón». En I948 el edificio preexistente recibe la visita del inspector del Gobierno Civil de Cáceres J. Cabrera, quien denuncia que la sala no cumple la legislación vigente. Así pues, en ese mismo año la administración provincial requiere a su propietario, Pedro León Acacio, que proceda a la reforma del local. En 1949 Perianes es requerido para la reforma. En la visita de la inspección del año I950 se certifican las condiciones idóneas del lugar (AHPCC-GC.2049).

Para el análisis arquitectónico del cinematógrafo en cuestión contamos con dos documentos de primera mano: por una parte, la memoria y los planos ejecutados por Perianes, y por otra, y de forma complementaria, el proyecto de instalación

24. Vid. García-Manso, Angélica: «Los cines parroquiales de la Diócesis de Coria-Cáceres: una reconstrucción documental desde las Ciencias Sociales», Boletín de la Real Academia de Extremadura de las Letras y las Artes, 24, 2016, pp. 219-246. 
eléctrica elaborado por el perito industrial Tomás Civantos, con quien colaboraba de continuo Perianes (AHPCC-GC.2049).

La razón de que el antiguo salón de baile no cumpliera la legislación entonces vigente y que obligó a la reforma del edificio residía en que «El Corralón» tenía un único acceso, a través de la Calle Corralón, la cual toma su nombre precisamente de este local de espectáculos, y carecía, pues, de una salida de emergencia que permitiera la evacuación del público llegado el caso. La creación de dicha salida de emergencia fue el aspecto que determinó toda la remodelación llevada a cabo por Fernando Perianes. Así pues, el «Cine España» de Torrejoncillo es un edificio de dos alturas al que se accedía por dos calles perpendiculares, la ya mencionada Calle Corralón y la Calle Capitán Corvín (actual Calle Amargura).

No obstante, en apariencia, en su proyecto Perianes apenas trabaja en el exterior del inmueble del Cine España; éste da a dos calles y contaría con dos posibles fachadas (de hecho, la zona de taquillas y la zona de bar se encuentran en calles diferentes, y la entrada obliga a un paso enrevesado a través de escalones y pasillos). El doble acceso del inmueble queda mejor reflejado en la documentación del perito Civantos, quien en su memoria describe el acceso al anfiteatro a través de dos escaleras, una que parte desde el vestíbulo y otra desde el patio exterior. No obstante, la intervención exterior, aunque más puntual, refleja las dotes de Perianes a la hora de enriquecer la ubicación de accesos y taquillas en un callejón sin salida (Calle Corralón); la resolución que hace a este respecto es clave a la hora de entender el tratamiento ornamental del entorno urbano por parte del aparejador objeto de estudio.

Así, en lo que respecta al interior, aparte de adaptar la platea de forma atonelada propia de los antiguos espacios teatrales y de planear una nueva cabina, lo más llamativo lo presenta el acceso a la sala, que, de alguna manera, viene a ser, aunque cubierta, la auténtica fachada del cine. El diseño de este vestíbulo constituye una de las aportaciones más originales del aparejador al nuevo edificio, ya que lo concibe como una especie de pronaos a la que dota de una especie de frente propio, realmente elaborado, con una serie de vanos cuadrados que flanquean la puerta de entrada en disposición simétrica a ambos lados. Por lo demás, El diseño de este escenario que enmarcaba la pantalla estaba directamente inspirado en la embocadura de arco de medio punto que Ángel Pérez concibiera para el mítico «Cine Norba» de Cáceres, modelo que Perianes utiliza en otros edificios como el Cine España de Alcuéscar o el Ideal Cinema de Ceclavín.

En cuanto a la parte visible del cine, Perianes actúa, sobre todo, en el callejón que había dado nombre al antiguo local de ocio destinado a baile, teatro, proyecciones, etcétera. Su intervención, al margen de las taquillas y el ancho y formato de las puertas para un acceso o evacuación más acorde con las normativas de seguridad, se centra en el frente, que elabora mediante una celosía de ladrillo como elemento decorativo central. Se trata de una celosía que Perianes repetirá en el cine de Aldeacentenera, que se convierte en el icono del edificio y que, en el contexto urbano, posee una enorme fuerza visual, más aún cuando se trata de un callejón, desde el que se define la singularidad del inmueble, su carácter social. En relación con la remodelación del Cine Mendo de Coria ya hemos comprobado la inspiración en una hornacina 
eclesiástica que posee el frente del edificio; pues bien, la idea de asociar el icono del inmueble con un motivo de inspiración religiosa por parte de Perianes procede de su trabajo en el Cine España de Torrejoncillo. Ciertamente, el efecto de celosía que sobresale sobre la altura del edificio convierte el motivo en una especie de estandarte construido en fábrica de obra. Pero es que el propio juego de broca que dibuja Perianes se inspira en el pendón de la festividad más célebre y tradicional en la población, la conocida «Encamisá», que se celebra anualmente en el mes de diciembre con motivo de la Inmaculada; así, el estandarte es evocado de forma esquemática, según se puede comprobar en la contraposición de imágenes que acompaña las presentes reflexiones (Fig. 8).
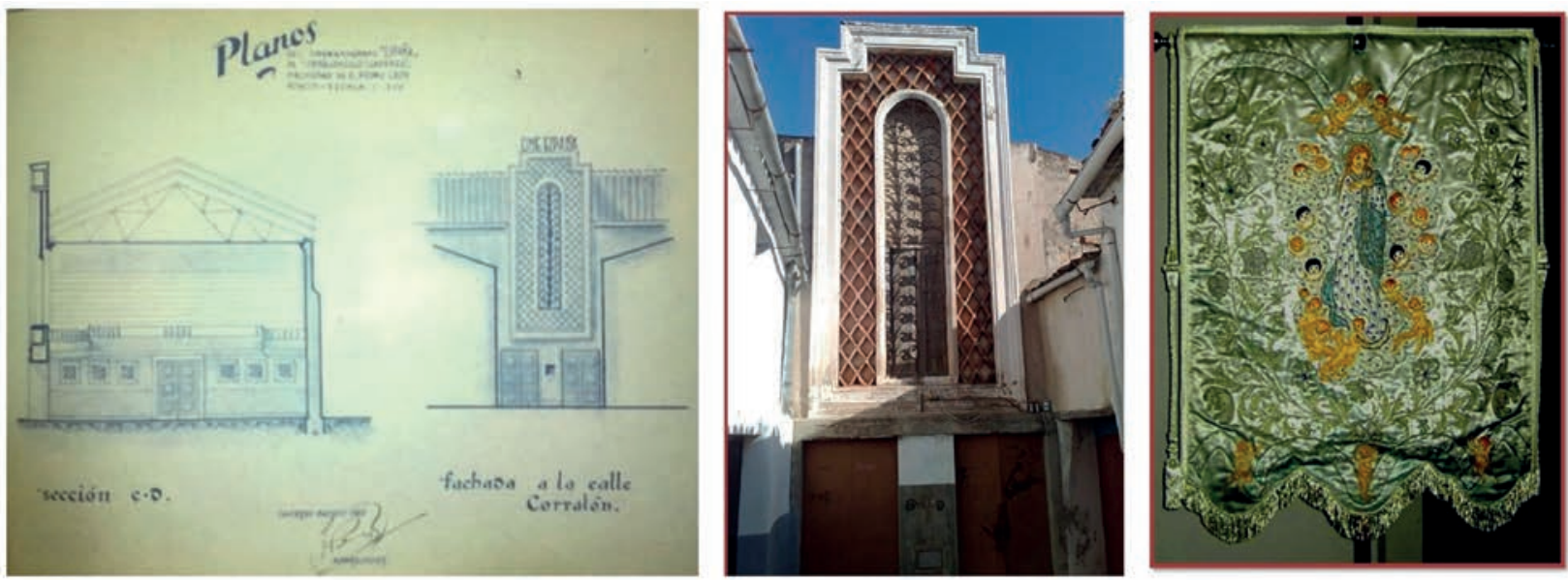

FIGURA 8. TORREJONCILLO. ARCHIVO HISTÓRICO PROVINCIAL DE CÁCERES (AHPCC), FONDO GOBIERNO CIVIL (GC): AHPCC-GC.2049. Fotografía de la autora y Estandarte de la Inmaculada, fotografía sin copyright conocido.

\subsection{VALDEFUENTES. CINE COLORINA}

La intervención de Fernando Perianes sobre el Cine Colorina de Valdefuentes ofrece una situación realmente singular, por cuanto se trata del traslado de un cinematógrafo; es decir, de un cambio de sede, desde la ocupación de un espacio en un inmueble monumental cercano, fechado en el siglo XVI, hacia una casa solariega o burguesa, construida a principios del $\mathrm{XX}$, que será reformada como espacio para proyecciones. Así, en el mes de noviembre de 1958 presenta Perianes la «Memoria» para el traslado del Cine Colorina del número 2 al número 5 de la Plaza de España de Valdefuentes, dadas las reducidas dimensiones del local previo además de los inconvenientes del trabajo sobre un entorno palaciego. Los verbos en futuro reflejan que se trata no de una certificación, sino de una propuesta de reforma en el nuevo emplazamiento. Es en agosto de 1959 cuando, ahora sí, se certifica la obra acabada (AHPCC-GC.2052).

La propuesta de Perianes en el aspecto externo pretende mantener el aire monumental del entorno de la plaza (actual Plaza de España), muy cercana al Convento de San Agustín, casi en sus estribaciones, conocido popularmente como el «pequeño Escorial» cacereño. De ahí que su intervención se base en un aspecto decorativo 
sobre la casa burguesa o casón que acoge el nuevo cine, estableciendo un diálogo perpendicular entre la monumentalidad de la Casa-Palacio de los Sande, en uno de cuyos portales cegados se asentaba el antiguo cine y la reforma en el casón; se trata de la coronación del edificio con una cenefa o crestería atrebolada que busca emular la fábrica de piedra dominante en el enclave del conventual y la casa de los Sande.

La crestería que corona el frente del edificio que da a la plaza viene a replicar la cenefa plateresca con motivos de fauna fantástica que corona la fachada el Palacio de los Golfines de Abajo anexo a la sede de la Diputación Provincial de Cáceres en la que trabajaba el aparejador en pleno corazón de la ciudad monumental cacereña, elemento muy semejante a su vez al que se aprecia en el salmantino Palacio de Monterrey. En lo que se refiere al Cine Colorina, las diferencias del diseño entre la crestería plasmada en los alzados y la erigida es indicio de que no existía antes de la reforma de Perianes, o, en todo caso, de que se podría tratar de una crestería diferente, cambiada durante el proceso de reforma, de tal manera que una crestería ondulada y encalada fuera cambiada por otra de reminiscencias pétreas. Por lo demás, los rebordes de los arcos de las ventanas no dejan de responder a los de las propuestas habituales del aparejador, aunque pueden pertenecer también al diseño originario. Al cabo, se logra integrar un edificio de ocio en un entorno de burguesía rural y de monumentalidad aristocrática (Fig. 9).
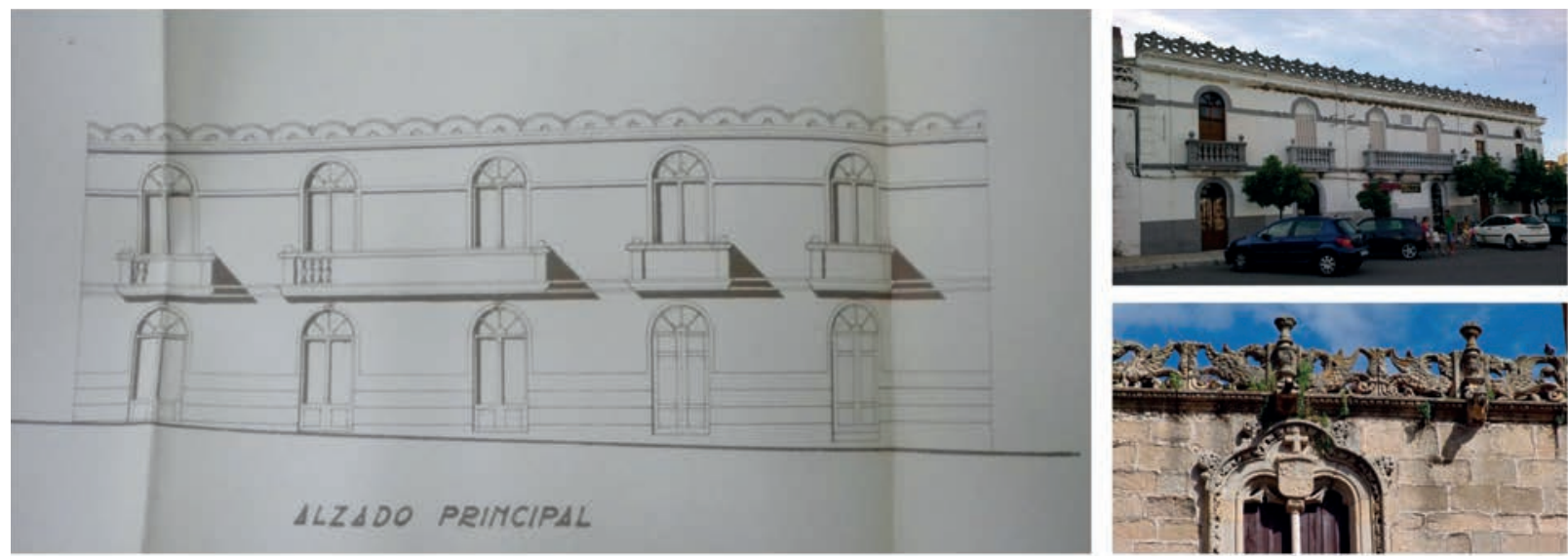

FIGURA 9. VALDEFUENTES. ARCHIVO HISTÓRICO PROVINCIAL DE CÁCERES (AHPCC), FONDO GOBIERNO CIVIL (GC): AHPCC-GC.2052. Fotografías de la autora.

\subsection{VALVERDE DEL FRESNO. CINES LAJAS Y PORTUGAL/PARAMIO/MARÍA LUISA}

Valverde del Fresno se cuenta entre las localidades cacereñas que contaron con proyecciones cinematográficas más o menos estables con anterioridad a la Guerra Civil, en el Cine Salón Teatro de Antonio López. Con posterioridad, en i944, el promotor Eugenio López Lajas adaptó el espacio de su salón de bailes como lugar de espectáculos, es decir, para representaciones y proyecciones. El local, un inmueble de arquitectura rural, se encontraba en el interior de la población, prácticamente en su centro urbano (en las traseras del ayuntamiento, en la actual calle Maestro 
Don Manuel Fernández; entonces Hernán Cortés). Un lustro después, en los años I948-I949, Antonio Lajas Núñez lo convierte en el «Cine Lajas», a pesar de no ser un cinematógrafo de envergadura, pues cuenta con un aforo de en torno a doscientas butacas. Con la erección del Cine Paramio, Valverde contará con dos cinematógrafos en los años cincuenta del pasado siglo, con fuerte competencia comercial entre ellos. Pues bien, tanto en la construcción del Cine Paramio como en la reforma final del Cine Lajas -con el fin de adaptarlo a la normativa-, intervino Fernando Perianes. Así, en lo que se refiere al Cine Lajas, la solución que adopta Perianes se presenta como meramente funcional, como un mero intento de aportar modernidad sobre la pequeña fachada de acceso, además de las relativas a las necesidades de seguridad. El cine será clausurado en 1975 y reformado como local comercial.

La segunda intervención mencionada se fecha un año después, a finales de I95I y a lo largo del año siguiente, y es de mayor envergadura, además de potenciar urbanísticamente una arteria de expansión de la población, en una de sus calles de acceso al centro. Se trata del ya citado Cine Paramio. La propuesta de Perianes parece justificar la intervención sobre un local previo, pero, en el fondo, se propugna un nuevo inmueble, por cuanto la reforma afecta a las crujías entre los muros de contención y supone la elevación de la altura del edificio de la Avenida Don Santos Robledo. Se trata del Cine Paramio, por el nombre de su promotor, conocido como Cine Portugal en los planos del aparejador y que también conocerá el nombre de Cine María Luisa. Las variaciones en el nombre son indicio del papel del aparejador, que reforma un local preexistente al que confiere un nombre rayano que no es, al cabo, el que termina siendo referente del edificio, Paramio, por el apellido de su promotor. Por lo demás, el inmueble inicial se aprecia en la ortofotografía del vuelo del año I945-1946. El edificio en la actualidad se encuentra en ruina irreversible excepción hecha de su frente.

Tres son los documentos que firma Perianes: la «Memoria descriptiva», en diciembre de I95I, en la que informa sobre el proceso de reforma, una «Ampliación de la memoria», fechada marzo de 1952 (documento realmente llamativo no sólo por lo poco habitual del requisito cuanto porque es donde se informa, entre otros aspectos de la edificación, sobre el anfiteatro, tal como había solicitado el arquitecto Ángel Pérez en el mes de enero de 1952 con el fin de autorizar desde el Gobierno Civil el nuevo uso del inmueble), y, finalmente, el «Certificado de obra», cuya rúbrica se fecha en junio de I952 (AHPCC-GC.2054).

Desde la primera línea de la «Memoria descriptiva» se informa de que se trata de un «local que se pretende adaptar para cine», expresión que, junto al uso de verbos en tiempo futuro, denota el carácter creativo de su intervención; y, sobre todo, la importancia de actuar sobre las crujías. La elevación de la altura tendrá su reflejo en el frente del edificio. Así, la fachada posee una geometría recta, casi afilada, como en el caso del Cine Salamanca de Zarza la Mayor. Por lo demás, la celosía encastrada, cuyo ancho coincide con el del dintel, ofrece un aspecto de hornacina al frontal del cine. Ello, al igual que se ha propuesto en relación con el Cine Mendo de Coria, invita a una inspiración casi de retablo para el diseño. Por lo demás, las embocaduras de las taquillas se presentan en forma de arco y rompen con la geometría recta del conjunto. En el color de la pintura de azul patinado, de acuerdo 
con los restos que permite entrever la incuria del tiempo, se percibe la influencia del Cine Norba de la capital cacereña. Por lo demás, el edificio se presenta en el continuo de la calle como una transición entre las construcciones rurales y otras de fábrica de mayor envergadura. El leve hundimiento del lienzo central, con una celosía cuadrada enmarcada, siendo la celosía marca en cinematógrafos como el Cine Mendo de Coria, el Cine España de Torrejoncillo o el Cine Salamanca de Aldeacentenera, constituye el elemento más representativo, pues, de la fachada, confirmado además por su coincidencia en paralelo con el dintel escalonado, como también plantea Perianes en el Cine Avenida de Zorita, si bien en el cinematógrafo zoriteño el motivo central carece de celosía, trocada en ondulación. De cualquier forma, al igual que en lo relativo a los citados Cine Mendo de Coria, al Cine España de Torrejoncillo o el también mencionado Cine Avenida de Zorita, el aparejador busca un elemento característico de la población con el que dotar de personalidad el frente del cine y lo encuentra en enclaves religiosos.

Así, el edificio más significativo de Valverde del Fresno probablemente sea la Iglesia de Nuestra Señora de la Asunción, de los siglos XV-XVI, aunque su singularidad proceda en buena medida en su carácter inacabado: el resultado es fuertemente geométrico, no sólo por la inspiración herreriana del templo, sino por la contraposición entre portada y cabecera, con una nave central que aparece hundida, con una techumbre más baja de la que se esperaría en función de la prominencia de los extremos. El edificio, visto desde la distancia, ofrece un llamativo efecto de acordeón, efecto que también se descubre en el planteamiento que sugiere Perianes mediante el juego geométrico de la fachada del Cine Paramio (Fig. Io).
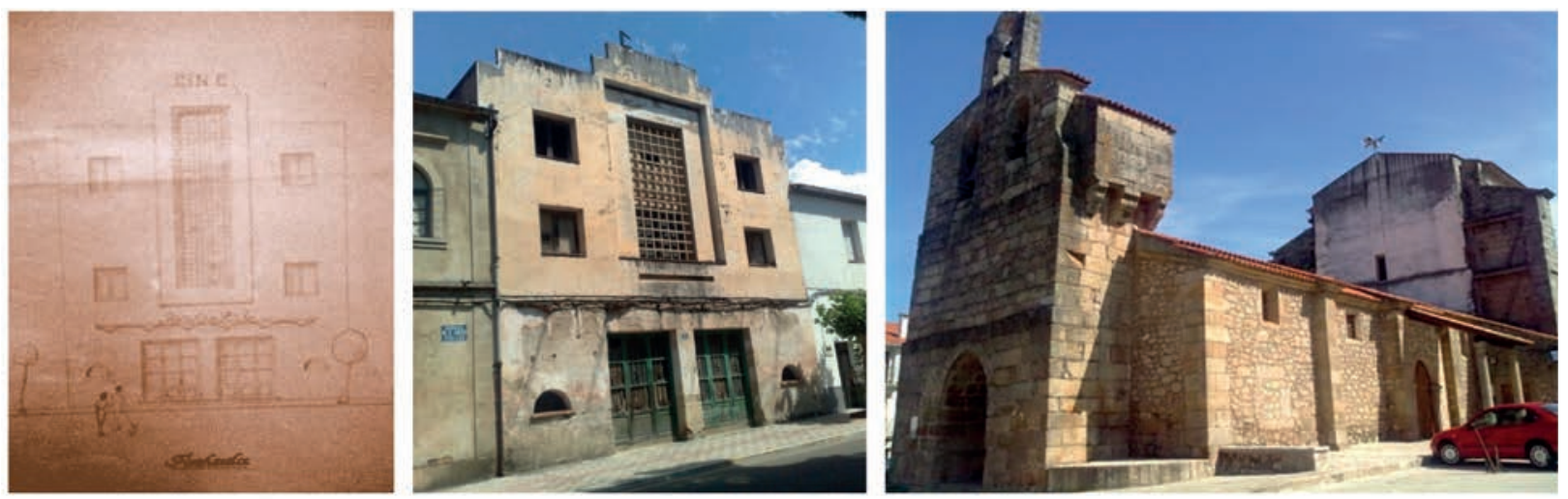

FIGURA 1O. VALVERDE DEL FRESNO. ARCHIVO HISTÓRICO PROVINCIAL DE CÁCERES (AHPCC), FONDO GOBIERNO CIVIL (GC): AHPCC-GC.2054. Fotografías sin copyright conocido.

\subsection{ZARZA LA MAYOR. CINE SALAMANCA}

El Cine Salamanca de Zarza la Mayor representa para Fernando Perianes llevar a cabo un proyecto de construcción en su localidad de origen, además de ser, probablemente, de los primeros cinematógrafos que erigió, si no el primero de nueva planta. La ortofotografía del vuelo de I945-I946 carece de nitidez suficiente, muy 
desenfocada y en condiciones de luz probablemente desfavorables; aun así, se aprecia el trazado de las calles, hecho importante este por cuanto se trata de espacios más claros que los relativos a edificaciones propiamente dichas. Pues bien, en el espacio del Cine Salamanca se aprecia una zona blancuzca que puede implicar la existencia de un solar ya en desmonte, si no en construcción, pues el cine comienza su andadura probablemente en el año I947. La ubicación del cine se encuentra en una zona de crecimiento urbano, en la actual Avenida del Doctor Perianes, perpendicular a dos calles de acceso al centro, en un espacio de cruce amplio. El nombre del cinematógrafo procede, seguramente, de los orígenes del médico promotor de la exhibición cinematográfica, Mario Guillén, quien lo erige como negocio familiar, el cual, además, según hemos señalado, expandirá a la cercana localidad de Ceclavín. La propia Zarza la Mayor no carecía de tradición de exhibición de películas, pues, con anterioridad al Cine Salamanca, desde las primeras décadas del siglo XX contaba con un salón tradicional en pleno centro de la población, junto a la Iglesia, que era conocido con el nombre de Cine Clavero o Cine Zarza, cuyo promotor se llamaba Serapio Bofill.

El Cine Salamanca ofrece una fachada cuadrada, organizada en tres lienzos verticales y dos cuerpos, con una estructura visual de seis espacios, separados por rebordes lisos encastrados, como campos de un escudo heráldico. Un estrecho balcón almenado que cruza la fachada a manera de marquesina y un leve frontón que corona el frente del cinematógrafo organizan la disposición de las ventanas: tres aspilleras en cada uno de los extremos superiores, sobre los lienzos exteriores, que sobresalen levemente en forma de torres. De alguna manera, mediante el aspecto heráldico, la propuesta de torres y aspilleras, las almenas de la balconada-marquesina, etcétera, Perianes pretende conferir un aspecto monumental al edificio. Y es que, en efecto, la proporción cuadrada aporta de por sí un carácter macizo al inmueble.

A este respecto, el inmueble busca dialogar con el entorno de una población que, como Zarza la Mayor, es rica en patrimonio arquitectónico, destacando en éste la Iglesia de San Andrés, del siglo XVI. Aunque el cinematógrafo se presenta como un monumento civil, no mencionamos el edificio eclesiástico por casualidad: la coincidencia de distribución de los cuerpos de la fachada de San Andrés y de las robustas columnas adosadas que escoltan como torres el lienzo central con los de la fachada del Cine Salamanca revelan una proximidad bastante palpable si se enfrentan las fotografías de uno y otro, demostrando que el Cine hace una evocación evidente de la iglesia, es decir, que se inspira en ésta; de ahí también la geometría entre cuadrada y rectangular que impera en sendos edificios. El aparejador conocía bien el inmueble eclesiástico; ello no sólo por sus orígenes, sino porque entre sus primeros trabajos tras la culminación de sus estudios se contó una intervención en el interior de la misma iglesia. Es más, de tratarse de su primer cinematógrafo, de alguna manera Perianes encuentra una forma de dialogar con el entorno que, según hemos estado considerando, caracteriza su poética constructiva (Fig. II). 

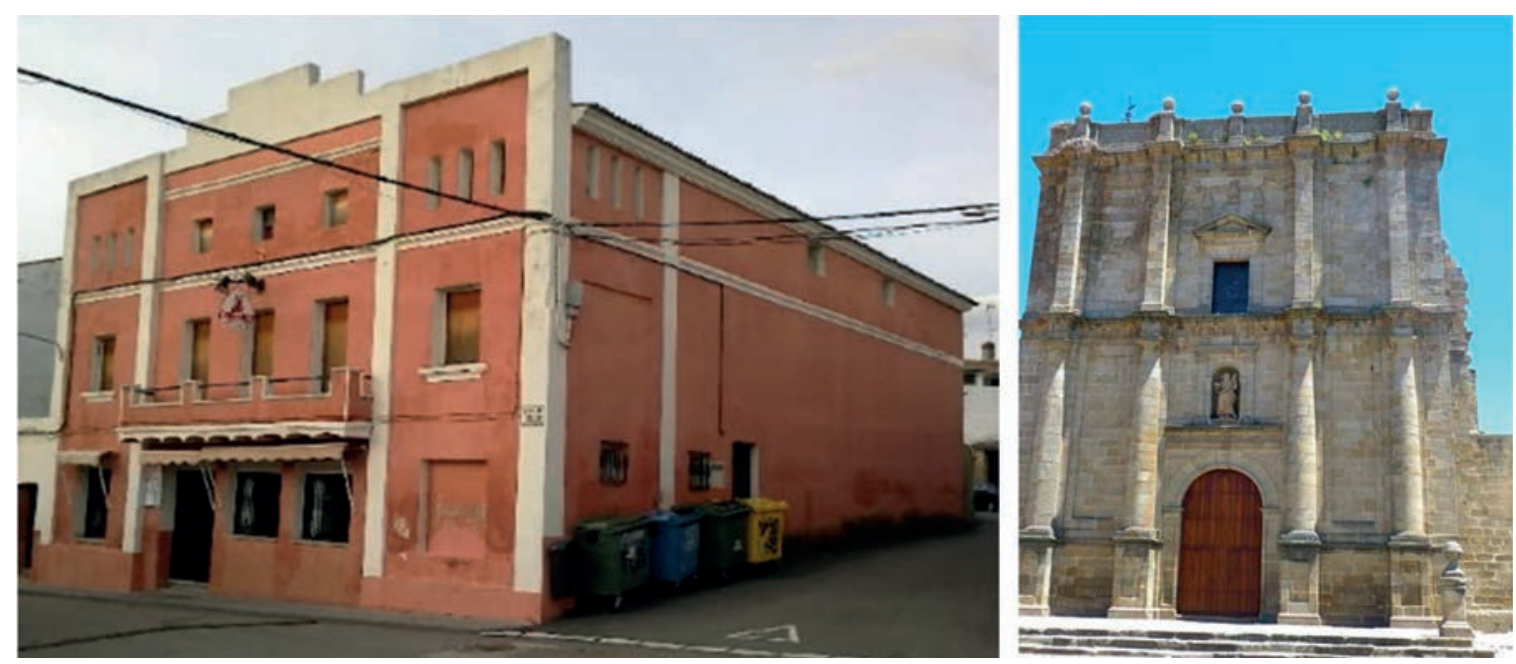

FIGURA 11. ZARZA LA MAYOR. Fotografías de la autora.

\subsection{ZORITA. CINE AVENIDA}

La documentación con que se cuenta en torno a la puesta en marcha del Cine Avenida de Zorita refleja de manera sintomáticamente precisa las formas de actuación burocrática por parte de Fernando Perianes con el fin de soslayar su condición de aparejador para intervenir como auténtico arquitecto y proyectista de los edificios que diseña. De hecho, el proyecto final aparece firmado por el arquitecto Ángel Pérez, cuando la construcción es previa y de la exclusiva responsabilidad de Perianes. En otro lugar ${ }^{25}$ hemos detallado ya el proceso de erección y puesta en explotación del Cine Avenida de Zorita - en cierta manera, se trata del trabajo del que procede el presente estudio en su conjunto-, en virtud de la documentación detallada que afecta a la legalización a posteriori de un inmueble que primero se construye y luego se atribuye su proyección a un arquitecto de la talla del mencionado Ángel Pérez. Lo cierto es que corre ya el año I959 y no sólo Perianes ha depurado su trabajo, sino que el control administrativo se ha vuelto más exigente que doce años antes, cuando había entrado en funcionamiento el Cine Salamanca de Zarza la Mayor.

Según hemos destacado a lo largo del presente estudio, existen dos aspectos claves en los diseños de Fernando Perianes: la ubicación del inmueble en el entorno urbano -que, en el caso de Zorita, se produce prácticamente en la confluencia entre una calle y una de las avenidas centrales y carretera de la población, en una zona en la que se llegan a documentar entre los años cincuenta y sesenta hasta cuatro cinematógrafos (entre otros locales de ocio)- y cómo la fachada del edificio se presenta como foco de dicho entorno urbano. El frontal acanalado que caracteriza el centro de la fachada cinematógrafo puede inspirarse en el lugar

25. García-Manso, 2011, cit. 
más emblemático de la localidad, aunque se encuentra fuera de esta; se trata de la ermita de Fuente Santa, cuyo manantial se caracteriza por estar protegido por una balaustrada de piedra evocada en el motivo estético del frente del cine; se trata, como hemos destacado en otras ocasiones, de una propuesta de inspiración en las vivencias religiosas de la localidad ${ }^{26}$ (Fig. I2).
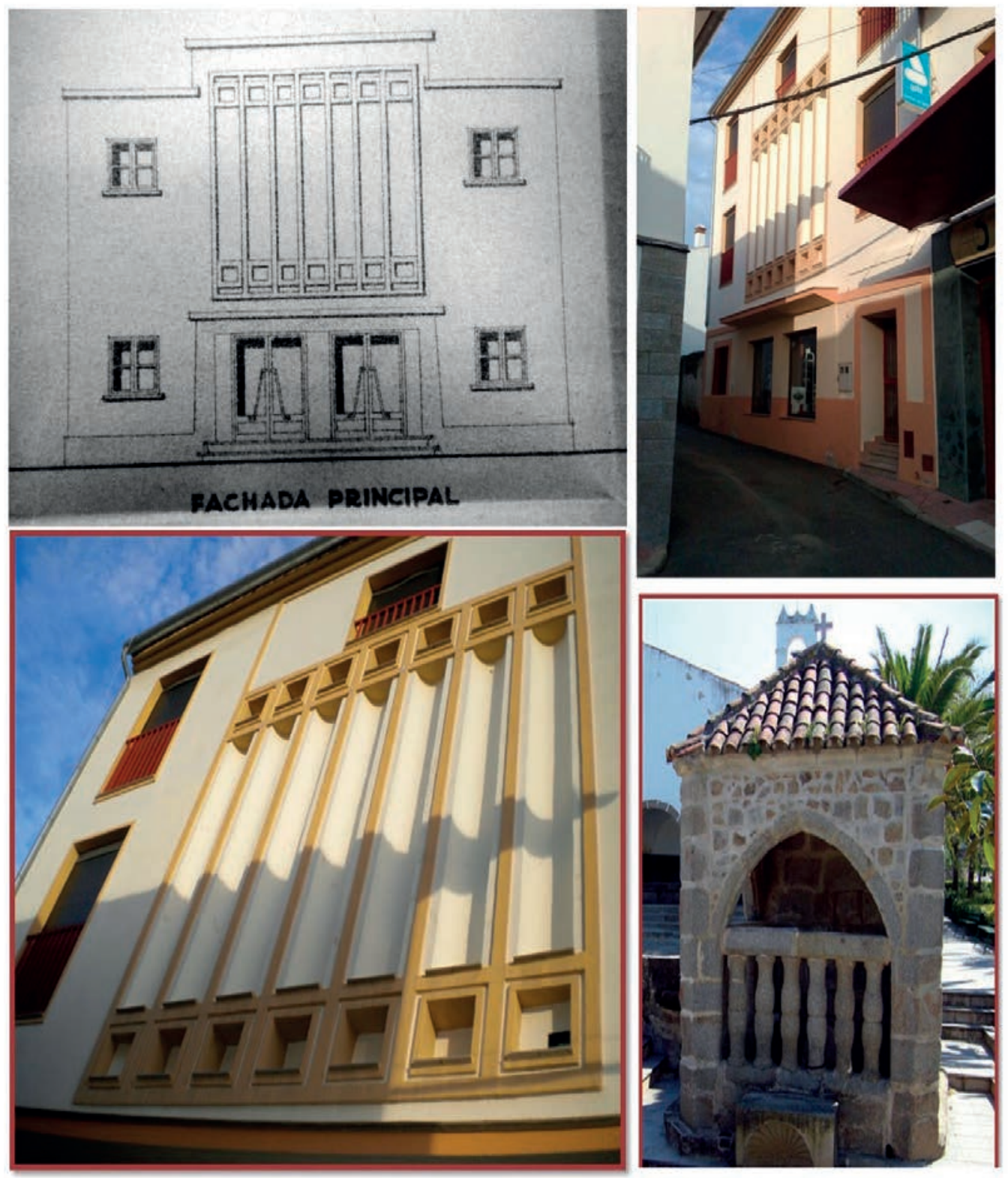

FIGURA 12. ZORITA. ARCHIVO HISTÓRICO PROVINCIAL DE CÁCERES (AHPCC), FONDO GOBIERNO CIVIL (GC): AHPCC-GC.2056. Fotografías de la autora.

26. Cf. Ramos Rubıo, José Antonio: Zorita: Una antigua villa de la penillanura trujillano-cacereña. Cáceres, Diputación Provincial, 2016. 


\section{CONCLUSIONES}

Al margen de lo relativo a la construcción y funcionamiento de los locales de ocio en una región y una provincia eminentemente rurales en los momentos anteriores a la fuerte emigración de los años sesenta, la atención a los inmuebles diseñados por el aparejador Fernando Perianes en la provincia de Cáceres se presenta como indicio de un planteamiento urbanístico y estético singular, merecedor de atención por sí mismo. Así, en su producción se funden posibilidades de índole muy distinta: desde la reforma puntual, en las que se inicia, caso de Acehúche o el cine del poblado de colonización de Vegaviana, a la integral, como reflejan sus intervenciones en Coria o Torrejoncillo, por poner dos ejemplos, y el proyecto de edificios de nueva planta (Albalá, Aldeacentenera, Ceclavín, Zarza la Mayor o Zorita); desde edificaciones en entornos céntricos (reforzando un enclave monumental, como sucede en Valdefuentes) a zonas de acceso y crecimiento de las poblaciones (Aldeacentenera, Cañamero, Ceclavín o Valverde del Fresno); desde su trabajo para arquitectos como Ángel Pérez o Fernando Hurtado hasta propuestas propias camufladas bajo firmas ajenas o bajo legalizaciones de inmuebles supuestamente preexistentes.

La docena larga de cinematógrafos considerados en nuestro estudio se puede complementar con el análisis de otros trabajos, exclusivamente profesionales ya, que Perianes desarrolló en el Cine Morán, de Malpartida de Cáceres, o el Cine Ana-Mary de Alcuéscar, así como el de la puesta en marcha de salas de proyección en poblados de colonización recién inaugurados, alguno tan emblemáticos como el de Vegaviana, con su Cine Seco. Ello sin olvidar intervenciones en poblaciones de la provincia de Badajoz, aunque ciertamente «rayanas» como es el caso de San Vicente de Alcántara.

En otro orden de cosas, se puede decir que, desde una perspectiva geográfica, cuatro son los entornos comarcales de la producción de Perianes, que logra gracias a sus contactos con la administración provincial para la que trabaja: el entorno de Villuercas (con Zorita y Cañamero), del Alagón (con Coria y Torrejoncillo como referentes), de la Sierra de Montánchez (caso de Valdefuentes y, en particular, del hermoso Cine España de Albalá) y, sobre todo, de «La Raya» (es decir, a las localidades del entorno fronterizo: Valverde del Fresno, Piedras Albas o Zarza la Mayor), que puede constituir su producción más numerosa, destacando en el conjunto el Ideal Cinema de Ceclavín; ello sin olvidar edificios tan singulares como los del Cine Salamanca de Aldeacentenera y reformas como las del Cine España de Aliseda.

La influencia más palpable procede del arquitecto Ángel Pérez, para quien trabajó y con quien colaboró Perianes: de alguna manera, el emblemático Cine Norba de la capital cacereña inspira fachadas como los de Ceclavín y Albalá, pero sus motivos estéticos están presentes en otros inmuebles, como el de Zorita. Coinciden Perianes y Pérez en los rebordes de las ventanas, según se expresa, por ejemplo, en Aliseda; se trata de unos rebordes de inspiración regionalista, que empleó el arquitecto riojano de Cáceres en otros edificios cuyo uso no era de ocio cinematográfico.

No obstante, lo realmente llamativo es, además de la capacidad de trabajo que asume Perianes, cómo el aparejador propugna la integración de sus edificios con su entorno buscando para ello un icono que, de forma más o menos subliminal, enlace 
el inmueble con la experiencia de quienes lo van a disfrutar. Se trata de motivos que afectan fundamentalmente a las fachadas y proceden de paralelismos religiosos, monumentales y geomorfológicos, los cuales pueden ser incluso reutilizados con posterioridad en otros proyectos, según hemos considerado. El propósito implícito resultante es el de establecer un diálogo entre modernidad y tradición, entre la novedad de la propuesta y la experiencia cotidiana de los habitantes de los pueblos que se convierten en espectadores cinematográficos.

Se trata de un diálogo que redunda en la recuperación «virtual», o, en otras palabras, de la memoria que los habitantes tienen del sentido de unos edificios que organizaron el diseño de las calles de una población, la modernizaron, establecieron semejanzas con la arquitectura de la capital, y, al cabo, supusieron un importante lugar de encuentro ${ }^{27}$. Todo ello incluso en el caso de los edificios ya desaparecidos, como sucede con el Cine Mendo, de Coria. El resultado, al margen del conocimiento académico e histórico, deriva en un storytelling o relato creativo, de acuerdo con el que las evocaciones icónicas que, según hemos visto, plasma Perianes en las fachadas de los cinematógrafos funcionan como una «mise en abyme» heráldica, como una divisa de la población. Las consecuencias narrativas y, en general, didácticas, responden a pautas metodológicas plenamente en vigor a fecha de hoy ${ }^{28}$; también a las propias de la nostalgia ${ }^{29}$.

27. Cf. García Doménech, Sergio: «Percepción social y estética del espacio público urbano en la sociedad contemporánea», Arte, individuo y sociedad, 26, 2014, pp. 301-316; GARCíA-MAnso, 2018, cit.

28. Cf. CALDERÓN ROCA, Belén: «La importancia de la historia en la educación patrimonial: herramientas didácticas para la atribución de valores al patrimonio urbano», Clio. History and History Teaching, 41, 2015, recogido en $<$ http://clio.rediris.es/n41/articulos/calderon2015.pdf> (consultado el 5 de julio de 2017).

29. Cf. Montero Díaz, Julio \& PAZ, María Antonia: Lo que el viento no se llevó. El cine en la memoria de los españoles (1931-1982). Madrid, Rialp, 2012. 


\section{BIBLIOGRAFÍA}

Anuario Cinematográfico Hispanoamericano. Madrid, Servicio de Estadística del Sindicato Nacional del Espectáculo, I950.

Arenas Cabello, Francisco Julio: «La titulación de Aparejador. Evolución histórica de sus atribuciones profesionales: desde el Decreto Luján de I855 hasta la Ley 38/1999 de ordenación de la edificación», Boletín de la Facultad de Derecho de la U.N.E.D., 26, 2005, pp. I5-3I.

Arias Romero, Salvador Mateo: Granada: Sociedad, Cine y Arquitectura. Granada, Zumaya Editorial, 20II.

BAlsalobre García, Juana María: Arquitectura de salones, pabellones cinematográficos y cines. Alicante, Universidad de Alicante, 2006.

Blanco Esteban, Óscar \& Román lbáñez, Wifredo: Castillos de ceniza. Historia de los cines en la Montaña Palentina. Salamanca, Cultura \& Comunicación, 2013.

Blanco-Lorenzo, Enrique M. \& Sabín Díaz, Patricia: «El hueco de fachada en la arquitectura del cine», en Álvarez Areces, Miguel Ángel (ed.), Patrimonio y arqueología de la industria del cine, Gijón, CICEES (Centro de Iniciativas Culturales y Sociales), 20I0, pp. I5I-I60.

CALDERón RocA, Belén: «La importancia de la historia en la educación patrimonial: herramientas didácticas para la atribución de valores al patrimonio urbano», Clio. History and History Teaching, 4I, 2015 recogido en <http://clio.rediris.es/n4I/articulos/calderon20I5.pdf $>$ (consultado el 5 de julio de 20I7).

Collantes Estrada, María Jesús: Arquitectura del llano y pseudo-modernista en Cáceres. Cáceres, Caja de Ahorros y Monte de Piedad de Cáceres, I979.

García Doménech, Sergio: «Percepción social y estética del espacio público urbano en la sociedad contemporánea», Arte, individuo y sociedad, 26, 2014, pp. 30I-316.

García-Manso, Angélica: «Arquitectura de ocio en Extremadura: El Cine Avenida de Zorita», Norba-Arte, 3I, 20II, pp. I65-I79.

García-Manso, Angélica: «Los cines parroquiales de la Diócesis de Coria-Cáceres: una reconstrucción documental desde las Ciencias Sociales», Boletín de la Real Academia de Extremadura de las Letras y las Artes, 24, 2016, pp. 219-246.

García-Manso, Angélica: «Didáctica del patrimonio: El Cine Wetonia y otros edificios de ocio de Joaquín Silos Millán», Norba-Arte, 37, 2017, pp. 26I-277.

GonzÁlez GonzÁlez, José Manuel: Arquitectura contemporánea en Extremadura. Mérida (Badajoz), Editora Regional de Extremadura, 201 .

Hurtado Urrutia, Miguel: «De nuestra memoria cultural. Ángel Pérez, Arquitecto (I897I977)», Ateneo, revista del Ateneo de Cáceres, II, 20I0, pp. Io-I3.

LozAno BARTolozzı, María del Mar: «Pérez Rodríguez, Ángel», Gran Enciclopedia Extremeña, 8. Mérida (Badajoz), Ediciones Extremeñas, I989-I992, pp. 89-90.

LozAno BARTOlozzı, María del Mar: «Urbanismo y arquitectura en Extremadura en torno a I898, una etapa de tránsito», Revista de Estudios Extremeños, 54, I998, pp. 973-гог6.

Lozano Bartolozzı, María del Mar: «Agua, higiene, espacio. Proyectos a caballo entre dos siglos del arquitecto Emilio $\mathrm{M}^{\mathrm{a}}$ Rodríguez en poblaciones de la cuenca del Tajo», Boletín de Arte, 34, 2013, pp. 135-160.

Lozano Bartolozzi, María del Mar \& CRUz Villalón, María: La arquitectura en Badajoz y Cáceres: del eclecticismo fin de siglo al racionalismo (I890-I940). Mérida, Asamblea de Extremadura, I995. 
Montero Díaz, Julio \& PAZ, María Antonia: Lo que el viento no se llevó. El cine en la memoria de los españoles (I93I-I982). Madrid, Rialp, 2012.

Narganes Robas, David \& Jiménez Berrocal, Fernando: El teatro en Cáceres. Archivos y documentación (1586-I926). Mérida, Junta de Extremadura, 2009.

PARedes Pérez, María Montaña: «Fuentes documentales para el estudio del cine en Cáceres», Balduque, 7, 2015, pp. I44-162.

Pérez Álvarez, Juan Antonio, Bascón Arroyo, Francisco Manuel, Crespo Pérez, Francisco Javier \& Charro Lobato, Cristina: «Project Casey Jones, I945-46: el vuelo histórico fotogramétrico de la serie A en España y sus aplicaciones cartográficas», Mapping, I59, 20I3, pp. I4-25.

Pérez Rojas, Francisco Javier: Art Déco en España. Madrid, Cátedra, I99o.

RAmírez, Juan Antonio: «Especie en extinción: de las grandes salas cinematográficas a los multicines», Arquitectura Viva, 6o, I998, p. II2.

Ramos Rubio, José Antonio: Zorita: Una antigua villa de la penillanura trujillano-cacereña. Cáceres, Diputación Provincial, 2016.

Ramos Rubio, José Antonio \& MÉndez Hernán, Vicente: «Aportaciones inéditas del Monasterio de San Francisco el Real de Cáceres. Planos», Alcántara. Revista del Seminario de Estudios Cacereños, 64, 2006, pp. 55-93.

Rosa Roque, Julio: Guía de Cáceres y provincia. Cáceres, a expensas del autor, I95I.

SÁız VIADERo, José Ramón (ed.): La exhibición cinematográfica en España: de los barracones de feria a los palacios de cine. Santander, Consejería de Cultura, Turismo y Deportes, 2009.

SÁNCHEZ-GarCíA, Jesús Ángel: «Las salas de cine en España: Evolución histórica, arquitectura y situación actual», Patrimonio Cultural de España, Io, 2015, pp. 97-I09.

VIRGós SORIANo, Luis Ignacio \& GARCía CEPEDA, Francisco: «La ortofotografía y la cartografía catastral», Catastro, 83, 2015, pp. 7-30. 



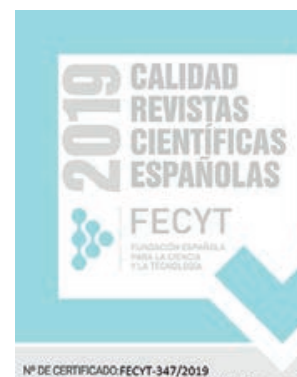

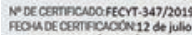

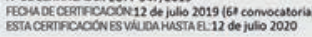

\section{SERIE VII HISTORIA DEL ARTE}

REVISTA DE LA FACULTAD DE GEOGRAFÍA E HISTORIA
AÑO 2019

NUEVA ÉPOCA

ISSN: $1130-4715$

E-ISSN 2340-1478

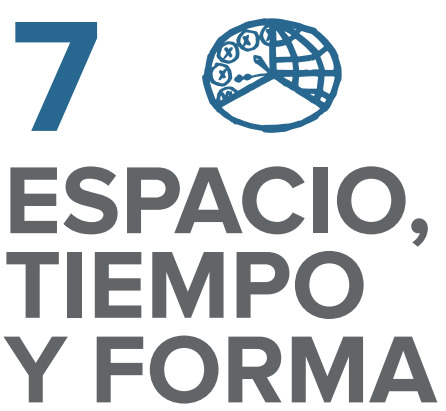

Dossier per Filippo Camerota: L'Apelle Vitruviano: Riflessioni sulla cultura architettonica dei pittori nella prima età moderna - El Apelles vitruviano: Reflexiones en torno a la cultura arquitectónica de los pintores de la Edad Moderna

17 FILIPPO CAMEROTA (GUEST EDITOR)

Introduzione. La prospettiva come tema vitruviano · Introduction.

Perspective as a Vitruvian Theme

1.1 Francesco P. DI TEOdoro (GUest Author)

- Due quæstiones vitruviane riconosciute: la base attica e il capitello composito nel terzo libro del De prospectiva pingendi di Piero della Francesca e un plagio conclamato di Luca Pacioli . Two Recognized Vitruvian Problems: The Attic Base and the Composite Capital in the Third Book of De Prospectiva Pingendi by Piero della Francesca and an Evident Plagiarism by Luca Pacioli

65 GIOVANNI MARIA FARA (GUEST AUTHOR) and Vitruvius

77 CARMEn GONZÁlez-ROMÁN

Metaescenografías pintadas · Painted Meta-scenographies

103

SARA Fuentes LÁZARO

Ad vitandam confusionem. Una aproximación analítica al tratado sobre perspectiva de Andrea Pozzo . Ad vitandam confusionem. An Analytical Approach to Andrea Pozzo's Treatise on Perspective

\section{Miscelánea · Miscellany}

133 ANTONIO PÉREZ LARGACHA

Art in Egypt. Ritual, Sense and Function

Predynastic

\section{Alejandra IzQuierdo Perales}

El templo de Hathor en Deir el-Medina: un estudio iconográfico en el

contexto de los templos ptolemaicos . The Temple of Hathor in Deir el-Medina: An Iconographic Study in the Context of the Ptolemaic Temples

191 JaIme Moraleda Moraleda

Ayuntamiento de Toledo. The Work of Miniatures for the Book of Vows of the City Hall of Toledo
209 Sergio Ramírez González, antonio Bravo nieto \& Juan ANTONIO BELLVER GARRIDO

La recuperación de dos repuestos de pólvora del siglo XVIII en Melilla: análisis y restauración - Recovery of Two Spare Gunpowder Warehouses from the XVIII ${ }^{\text {th }}$ Century in Melilla: Analysis and Restoration

231 Alejandro de LA Fuente Escribano

La restauración del castillo de Guadamur en el siglo XIX como in the XIX $X^{\text {th }}$ Century as an Expression of Romanticism in Spain

265 Paula Gabriela núñez, Carolina lema, Carolina Michel \& MAIA VARGAS

La construcción estatal patagónica en el siglo XIX. El dibujo como arte científico $€$ institucional . The Patagonian State Construction in XIX ${ }^{\text {th }}$ Century. The Drawing as Scientific and Institutional Art

\section{Guillermo Juberías Gracia} la zarzuela Pan y Toros (1864) en las colecciones municipales de Madrid · A Nineteenth-Century Vision of Charles IV Spain: Designs for the Zarzuela Pan $y$ Toros (1864) in the Municipal Collections of Madrid

311 Aurora Fernández Polanco

Ojos curiosos y capital: sobre el turismo visual decimonónico · Curious

Eyes and Capital: About Nineteenth-Century Visual Tourism

327 AngÉlica García-Manso

Los cinematógrafos diseñados por Fernando Perianes: una lectura patrimonial en torno a los edificios de ocio en la provincia de Cáceres. The Movie-theaters Planned by Fernando Perianes: A Heritage Reading around Leisure Architecture in the Province of Cáceres (Spain)

361 José-Carlos Delgado Gómez

y el médico y caricaturista José Delgado Úbeda «Zas» . The Humoristic Halls" during the Spanish Postwar Period (1940-1953) and the Doctor and Caricaturist José Delgado Úbeda «Zas»

379

IOANNIS MOURATIDIS

La dimensión espacial del «ser usuario de museo»: reflexiones sobre la The Space Dimension of «Being A Museum User»: Reflections on the Social Construction of an Inclusive Exhibition Space

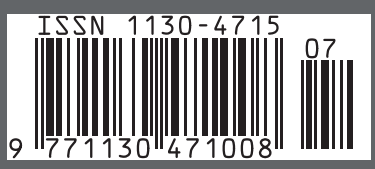


AÑO 2019

NUEVA ÉPOCA

ISSN: 1130-4715

E-ISSN 2340-1478

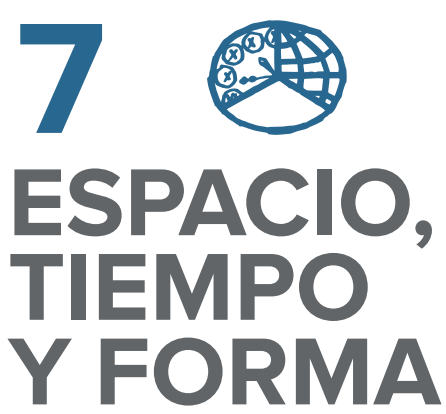

Reseñas · Book Reviews

4.07 Julia Fernández Toledano arte y la política en los tiempos del telón de acero. Madrid, Brumaria, 2019

\subsection{M. ${ }^{a}$ Cristina Hernández Castelló}

Leonardo da Vinci. Munich, Himer Publishers, 2018

\section{Francisco ORTS-RUIZ}

Mínguez, Víctor (dir.), El linaje del rey monje. La configuración cultural e iconográfica de la Corona aragonensis (1164-1516). Castelló de la Plana, Publicacions de la Universitat Jaume I, 2018. 